\title{
Microplastics in Latin America Ecosystems: A Critical Review of the Current Stage and Research Needs
}

\author{
Andreia N. Fernandes, ${ }^{\odot * a}{ }^{*}$ Crislaine Bertoldi, ${ }^{a}$ Larissa Z. Lara, ${ }^{a}$ Jéssica Stival, ${ }^{b}$ \\ Nortom M. Alves, ${ }^{a}$ Pedro M. Cabrera ${ }^{a}$ and Marco T. Grassi ${ }^{\odot b}$ \\ anstituto de Química, Universidade Federal do Rio Grande do Sul (UFRGS), \\ Av. Bento Gonçalves, 9500, 91501-970 Porto Alegre-RS, Brazil \\ ${ }^{b}$ Departamento de Química, Universidade Federal do Paraná (UFPR), \\ 81531-980 Curitiba-PR, Brazil
}

\begin{abstract}
The ubiquity of microplastics ecosystems has gained global attention. In this context, Latin America, which is responsible for $8 \%$ of the world's consumption of plastic material and has a small recycling rate $(4.5 \%)$, does not have enough data on microplastics contamination in its environmental matrices. This systematic review analyzed 196 studies from 16 territorials in Latin America and provided information about the current state of knowledge regarding the abundance, distribution, and associated impact of microplastics in different matrices. This review also describes the analytical procedures of sampling, extraction, identification, and characterization methodologies adopted by the literature review. The analysis shows that most of the studies that investigate microplastics abundance were carried out in the marine environment (59\%), and there is an insufficient investigation on microplastics abundance in freshwater bodies (16\%). Among all the studies, the highest microplastics concentration was observed in regions with high population density and/or in locations without proper sanitation and solid waste management. Additionally, the difference among microplastics abundance in the studies might be associated with the different analytical procedures employed to investigate microplastics. Lastly, knowledge gaps are identified, and recommendations are proposed to guide future studies on microplastics contamination.
\end{abstract}

Keywords: anthropogenic influence, analytical procedures, marine environment, freshwater

\section{Introduction}

The exponential growth of the plastic industry is a consequence of the remarkable features of plastic material as lightweight, resistance, low manufacturing costs, and versatility. ${ }^{1,2}$ Therefore, these materials are employed in many different areas of industry, agriculture, and medicine, where a large amount of the plastic manufactured is destined for packaging, comprehending products that are discarded in less than 1 year. ${ }^{3,4}$ Latin America is responsible for $8 \%$ of the global consumption of plastic material and produces more than 17,000 tons per day of plastic waste. ${ }^{5}$ Considering the small percentage of recycled wastes $(4.5 \%)$, most of these materials are incinerated or taken to landfills, where poor waste management results in large proportions of plastic wastes reaching the environment. ${ }^{6,7}$

*e-mail: andreia.fernandes@ufrgs.br

Editors handled this article: Eduardo Carasek and Maria Cristina Canela (Associate)
Most of the marine debris originates from land-based sources, once the mismanaged plastic might be transported through rivers and lakes to the oceans. ${ }^{6}$ Latin America comprises two out of the 20 most polluted rivers globally, estimated by the global plastic input model. ${ }^{8}$ The Amazon River that runs through Brazil, Colombia, Ecuador, and Peru is expected to contribute to the ocean with up to 63,800 tons of plastic waste every year, and the Magdalena River in Colombia with up to 29,500 tons of plastic waste. ${ }^{8}$

The accumulation of plastic litter includes debris in a wide range of sizes (macro, meso, micro, and nano), in which a great part is composed of microplastics, particles with a size length between 0.001 and $5 \mathrm{~mm} .{ }^{9,10}$ The research upon determination and quantification of microplastics has grown in the last two decades, evidencing that these plastic particles are ubiquitous in the environment, once their presence was already been reported in remote areas of the planet. ${ }^{11-13}$ The spread of microplastics in the environment is usually associated with anthropogenic activities, land 
use, and population density. Nevertheless, microplastics characteristics and environmental factors are also important elements that influence and control the distribution and presence of microplastics in the environmental matrices. ${ }^{14-18}$

The risks associated with microplastics contamination are widely reported since their presence in the environment might cause both physical and toxicological effects. Physical effects are the result of the microplastics ingestion by organisms which might lead to interior damage (e.g., block of the digestive tract, injuries, and false satiation). The toxicological effects are related to the potential toxicity of microplastics due to the release of compounds present in the plastic particles which are incorporated into it during manufacturing and its potential to sorb surrounding contaminants in the environment. Therefore, microplastics can act as routes for these contaminants, which can potentially be ingested by organisms, resulting in their bioaccumulation and biomagnification. ${ }^{19-21}$ Additionally, these particles also serve as microbe aggregating devices, being colonized by bacteria, algae, and other microorganisms that gather around the microplastics forming the plastisphere, raising the concern about transportation of pathogens and invasive species through environments, threatening the biodiversity. ${ }^{22}$ Microplastics can also threaten human beings since recent studies have already reported the presence of these particles in the human placenta and their genotoxic potential in human peripheral blood lymphocytes. ${ }^{23,24}$

Microplastics contaminations have been broadly reported throughout Europe, Asia, and North America; however, in the underdeveloped regions, research is still limited. ${ }^{25-28}$ The first study in Latin America regarding microplastics was in 2009, where Ivar do Sul et al., ${ }^{29}$ reported the presence of small plastic fragments and pellets on the beaches of Fernando de Noronha. Scientific research in microplastics had little attention in the following years in Latin America, evidenced by the lower scientific production (1-5 published papers per year). The significant increase of microplastics studies in the region occurred in the past 4 years, reflecting the rise of public concern about this ubiquitous contaminant. Nevertheless, the lack of microplastics knowledge on aspects such as occurrence, transport, fate, and impacts highlight that further investigation is urgently needed. Given these points, the present review aims to screen how research about microplastics in environmental samples in Latin America has been conducted. The following topics are presented: (i) summarize the main sampling, extracting, and characterization methods used in the different environmental compartments, (ii) provide a better understanding of microplastics contamination/abundance in Latin America countries, (iii) gather information on the studied impacts and toxicological effects caused by microplastics and (iv) identify the current gaps regarding these particles in Latin America.

\section{Literature Search and Article Metrics}

The literature search was systematically performed on two databases, Scopus and Web of Science, using keywords and phrases joined by Boolean operators "AND" and "OR". Title, abstract, and keywords were queried. The keywords used in the research process were: (microplastic* OR "microplastic* pollution" OR "plastic debris" OR "marine debris" OR "marine litter" OR microfiber* OR "plastic pellet*" OR "plastic fragment*") AND (freshwater OR "water column" OR "surface water" OR seawater OR sediment* OR beach* OR soil* OR "marine water" OR estuary OR bay OR "drinking water" OR river* OR stream* OR lake* OR brackish OR plastisphere OR runoff OR "storm water" OR accumulation OR ingestion OR gut OR stomach OR "digestive tract" OR "gastrointestinal tract" OR gill OR invertebrate OR vertebrate OR habits OR feces OR transfer OR trophic OR "food web" OR "food chain" OR ecotoxicology OR toxicity OR seafood OR genotoxicity OR intake OR diet OR "feeding behavior"). The keywords were selected to retrieve as many relevant publications as possible. Data filters were used to limit literature hits to peer-reviewed articles. In addition, we used country filters to select only articles from the Latin American region.

The literature retrieval was conducted from 1990 to 31 May 2021. It is important to highlight that in the present review, all the papers that investigate the presence of pellets were considered even if the microplastic term was not mentioned since it is reported in the literature that plastic pellets have sizes within the range of microplastics definition. The literature search yielded 518 records from Scopus and 636 from Web of Science. The records were exported to the Rayyan web app for data management and screening. After the screening, 196 studies were selected to perform the present review (Figure 1). For comparison purposes, some papers were chosen out of the study area (i.e., Latin America), and the selection criteria were based on the similarity with Latin America studies. Similar sampling, processing, data treatment, and presentation protocols were some of the applied criteria, such as environmental contaminants and compartments (e.g., freshwater, seawater, and soil).

The purpose of this research was to identify all available papers reporting microplastics abundance, distribution, effects, and associated contaminants in three different 


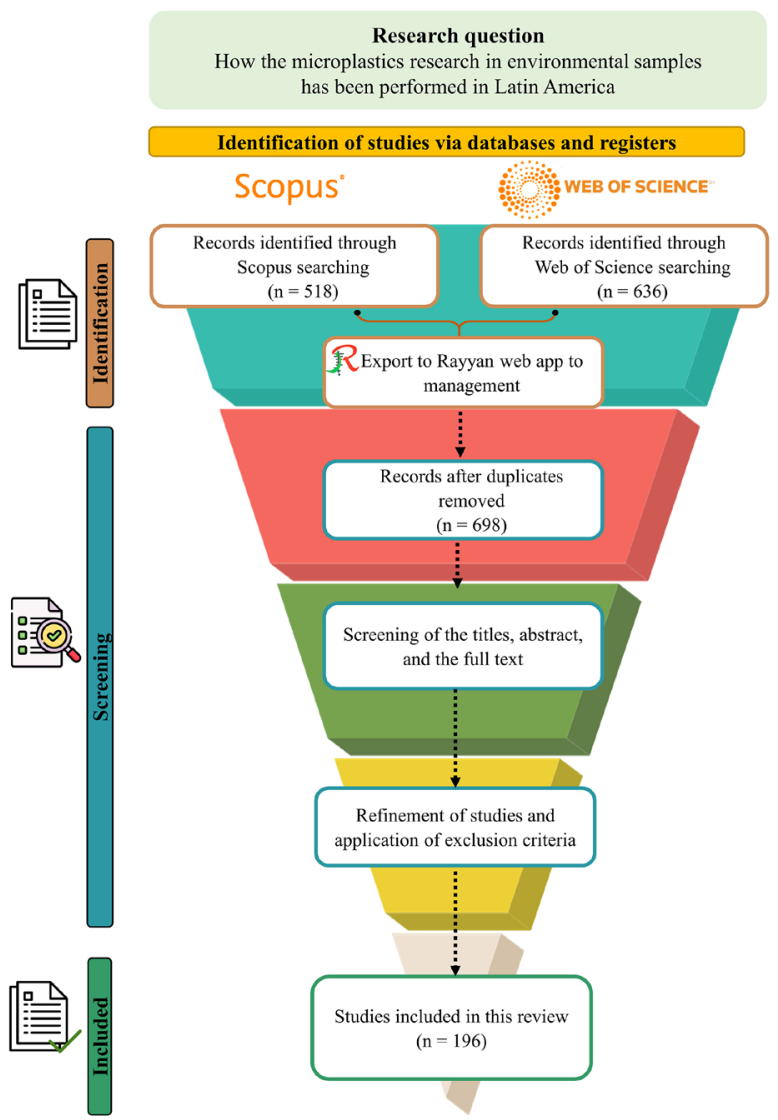

Figure 1. The literature retrieval process is used to find and analyze studies on microplastics in environmental samples from Latin America.

matrices, including water, sediment/soil, and biota. Among the studies under review, 24 performed investigations regarding microplastics in two or more categories of matrices. These papers were counted separately, which sums a total of 220 studies. Most studies (77\%) were published after 2018. Figure 2 shows all the reviewed papers with studies performed in the 16 Latin American territorials regarding microplastics and their relationship with the investigated matrices. Among all the studies, a total of $83 \%$ were conducted in four countries, where Brazil represents 53\%, Argentina 11\%, Chile 10\%, and Mexico 9\%.

\section{Analytical Procedures}

\subsection{Quality assurance and quality control}

Quality assurance (QA) and quality control (QC) are practices that should be considered early throughout any study. Therefore, in microplastics investigations, QA/QC are recommended to be included in sampling, extraction, and analysis processes. The quality control will undoubtedly improve and ensure the reliability and comparability of the obtained data. ${ }^{30}$ Thus, results of studies without the proper

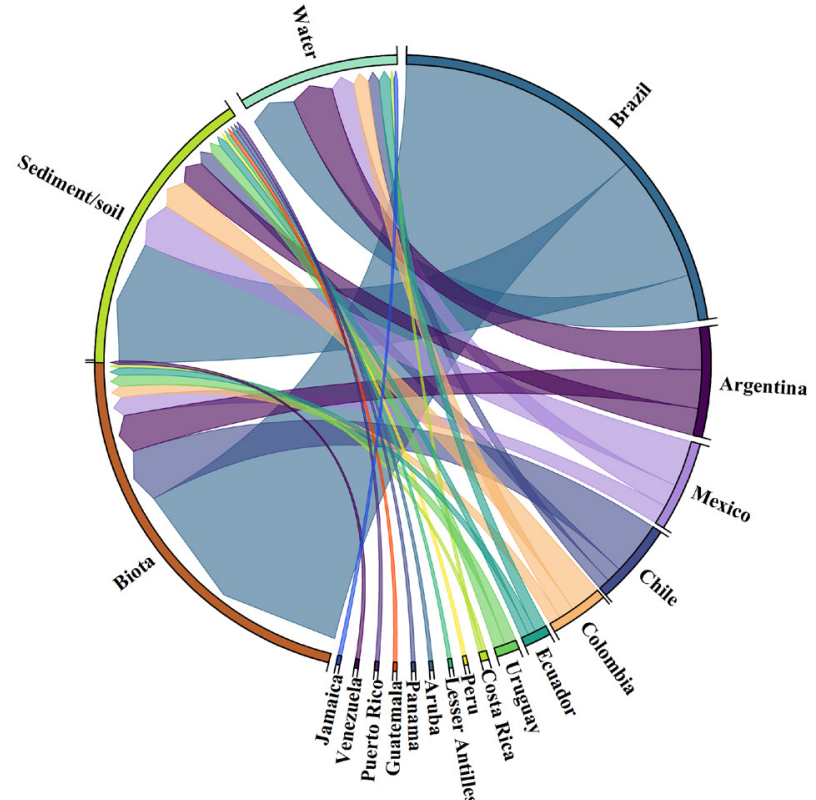

Figure 2. Cord diagram regarding the relation of countries and investigated matrices reporting the presence of microplastics. The width of each node is proportional to the number of studies.

procedures of contamination control measurement might demonstrate incorrect data about the assessment of the presence of microplastics in the ecosystem and its impact on the biota. ${ }^{31}$

The literature mentioned procedures, care, and steps that can be performed to improve the quality of data, such as $(i)$ all the team that will work with microplastics samples should wear cotton lab coats and nitrile gloves; (ii) if possible, the analysis should be done in a room with limited people and in a clean bench (i.e., laminar flow or safety cabinet); (iii) it is recommended that the materials used during the processes should be made of glass; (iv) all the working solutions, including the water, should be filtered (at least two times) on the same or smaller size pore size filters used for the sample, to ensure the absence of particles; $(v)$ all the material should be covered with tin foil and only opened when necessary with the intention to prevent airborne contamination; ( $v i)$ if possible, blank controls of the sampling collection and treatment should be used (i.e., controls of airborne contamination with open filters, and blank procedural with water samples).

Therefore, as the contamination cannot be $100 \%$ excluded, different controls are highly recommended. These procedures and care aim to evaluate all the possible sources of contamination (airborne, operator, and chemicals) during the processing of the microplastics samples. ${ }^{30-34}$ Among the articles under review, 90 studies mentioned at least one procedure or measure to prevent contamination ( $48 \%$ of the total studies that performed microplastics determination, 184 studies). Blanks with open filters to control the airborne 
contamination were employed in $29 \%$ and blank procedural in $26 \%$ among the studies under review. Other QA/QC, such as clean-up of the lab and filtration of reagents, were mentioned as well. The false-positive microplastics were excluded from the samples in the studies where significant contamination was detected. For instance, Castro et al. ${ }^{35}$ observed a level of contamination from airborne with open filters of 0.5 microplastic per sample, where 75 fibers were smaller than $1 \mathrm{~mm}$, and in general, the most common colors were blue and black. Neto et al. ${ }^{36}$ detected in their control with open filters a total of 28 particles with shapes similar to fibers and lines. It is also mentioned that even with quality measures, contamination is present, showing the ubiquity of plastics in the laboratory environment. ${ }^{37}$ These studies show the importance to carrying out QA/QC procedures to reduce microplastics contamination.

Additionally, in some studies, fibers were not taken into account in the total estimation of microplastics because of the risk of contamination from the airborne particles during the collection and processing of the samples. ${ }^{38,39}$ Since the literature already reported that fibers are the main microplastics present in the atmosphere, it is also assumed that they might represent a substantial source of airborne contamination during microplastics processing. ${ }^{40,41}$ Some reviewed studies considered contamination negligible when the number of items in the blank samples is significantly smaller than the particles observed in the samples. ${ }^{42}$ For instance, Birnstiel et al. ${ }^{43}$ observed two items in their control samples, which were considered negligible. Pazos et al. ${ }^{44}$ mentioned a number of 1 to 6 items in the control samples, which were also considered negligible in the total accounting of microplastics.

\subsection{Sampling procedure for microplastics}

The methods used to collect microplastics can broadly vary since they depend on the matrix to be sampled, the available instrument, and the size of microplastics to be targeted. In the studies under review, 184 among 220 performed the determination of microplastics in environmental matrices (water, sediment/soil, or biota). At the same time, 36 conducted investigations concerning impacts and toxicological effects caused by microplastics in organisms or the accumulation of contaminants in microplastics. Microplastics investigation was primarily performed in biota samples (41\%), followed by sediment/ soil (37\%) and water (22\%) (Figure 3). Marine and estuarine waters had the predominance, totaling 59 and $20 \%$, respectively, of the studies regarding the determination of microplastics. Investigation of contamination in freshwater was conducted in $16 \%$ among the reviewed studies and terrestrial samples in 5\%. These numbers highlight the need to carry out more studies in freshwater and terrestrial environments.

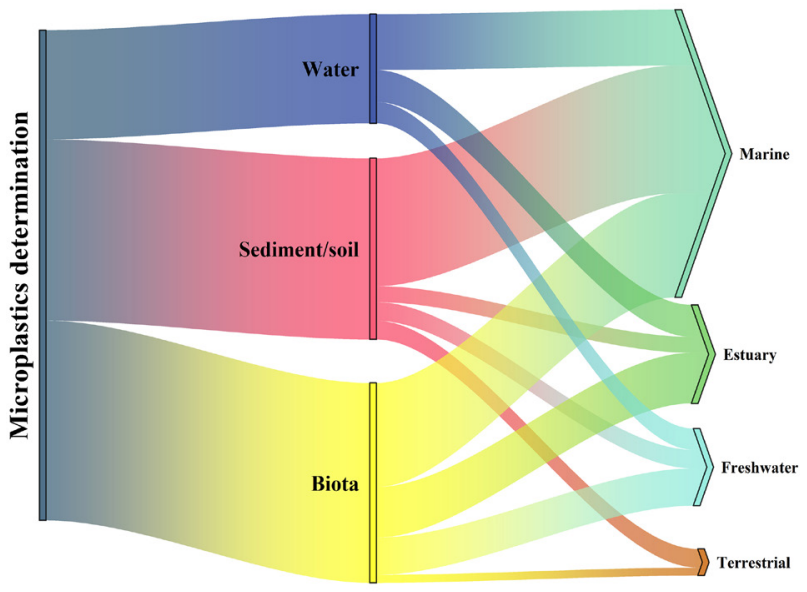

Figure 3. Distribution of publications regarding the microplastics determination in different environmental matrices $(n=184)$. Studies that performed investigation on more than one matrix are counted in each matrix node separately. The width of each node is proportional to the number of studies for that node.

The sampling of microplastics from aqueous matrices is usually described with water sampling from surface and subsurface. However, the distribution of microplastics can vary in the water bodies since their mobility differs mainly in terms of their shape, density, and composition. In the literature, there are many sampling procedures for collecting microplastics from water, usually performed with neuston, plankton, or zooplankton nets, which can collect a large volume of water and improve reproducibility. This procedure is often used to collect surface water samples; nonetheless, microplastics sampling with sieving, pumps, bottles, and buckets is used, allowing a more straightforward sampling of column water.

Microplastics from water bodies were predominantly collected with trawl nets (76\%); however, bottles (15\%) and buckets $(7 \%)$ were employed as well. The sampling depth is an aspect that must be considered but is not always mentioned ${ }^{45}$ The sampling depth was recorded in $48 \%$ of the studies and varied depending on the sampling procedure. The depth recorded varied from $0.20 \mathrm{~m}$ (sampling with trawls) up to $6.0 \mathrm{~m}$ (bulk sampling from the subsurface). The trawling duration varied from 3 to $60 \mathrm{~min}$, and the speed from 1 to 4 knots. In samplings with nets, $70 \%$ of the articles had mentioned using a flowmeter, $20 \%$ of the studies calculated just theoretically the water volume, $3 \%$ calculated the sampling area, and $7 \%$ did not mention how the volume was measured.

The size of microplastics found in the samples will depend on the mesh size employed during the sampling. 
Studies report the use of nets with pore sizes varying from 20 to $5000 \mu \mathrm{m}$. The nets between 300 and $350 \mu \mathrm{m}$ were the most used $(48 \%)$, followed by nets with a mesh size $<300 \mu \mathrm{m}(42 \%)$. However, it is important to highlight that the use of larger pore sizes can overlook smaller microplastics. Figueiredo and Vianna, ${ }^{46}$ conducted sampling with different mesh sizes (64 and $200 \mu \mathrm{m}$ ) and observed that microplastic particle abundance was ca. 1.5 to 6.8 -fold higher in samples collected with the $64 \mu \mathrm{m}$ mesh than in $200 \mu \mathrm{m}$ mesh net. In addition, it is mentioned that the use of nets with a small pore size (ca. $100 \mu \mathrm{m}$ ) can quickly clog during the sampling due to organic and mineral material in suspension leading to a reduction in the volume of water sampled ${ }^{47}$ Therefore, it is recommended that sampling with these nets should be performed for a short period of time. A solution may be the use of filtration or sieving with buckets which makes it possible to use smaller mesh. This type of sampling has the advantage of not requiring a vessel. On the other hand, they can be a time-consuming sampling strategy that generally collects lower water volumes than trawl nets samplings.

The distribution and abundance of microplastics in sediments/soils are influenced mainly by their characteristics and environmental factors such as wind and currents. ${ }^{48-50}$ Therefore, sediments are generally sampled from the beach or water bottom (ocean, sea, lake, and/or river), and the distribution is shown in Figure 3. Regarding marine environments, it is reported that tide line variation is an important factor in the distribution of marine litter on the beaches, highlighting the importance of evaluating the tide line in microplastics determination and distribution in these matrices..$^{51}$ Therefore, on beach samplings, a total of $52 \%$ of studies had mentioned the tide line, where $78 \%$ sampled microplastics in the high tide.

Sampling depth is another factor that should be evaluated. In the studies reviewed, $62 \%$ of all mentioned the depth of the collection. In general, the sampling depth varied between 0 and $1.50 \mathrm{~m}$, and most of the samples were collected in a single sediment depth up to $5 \mathrm{~cm}$ deep. One study ${ }^{52}$ collected sediment samples with $0.1 \mathrm{~m}$ depth intervals until a depth of $1.0 \mathrm{~m}$. Another study ${ }^{53}$ performed sand sampling at three depth strata $(0-20,20-40$, and $40-60 \mathrm{~cm})$. A third one ${ }^{51}$ collected samples at three different depth layers on the beach, surface column $(0-5 \mathrm{~cm})$, middle column $(6-19 \mathrm{~cm})$, and deep column $(20-25 \mathrm{~cm})$. The tools mentioned to sampling sediments were shovels, spatula, and core. Regarding samples collected from the bottom sediment, sampling was commonly performed with Van Veen grabs.

Distribution of studies in biota are also shown in Figure 4 and, regarding specimens, fishes were the most investigated organisms to quantify the contamination by microplastics, representing $53 \%$ of the studies, followed by bivalves, $11 \%$, and crustaceous, $10 \%$. Other organisms were also inspected, including tadpoles, turtles, birds, annelid, anemones, longnose stingrays, and marine mammals. The organisms were commonly captured in the field with nets, purchased in fish markets, or collected on the beaches.

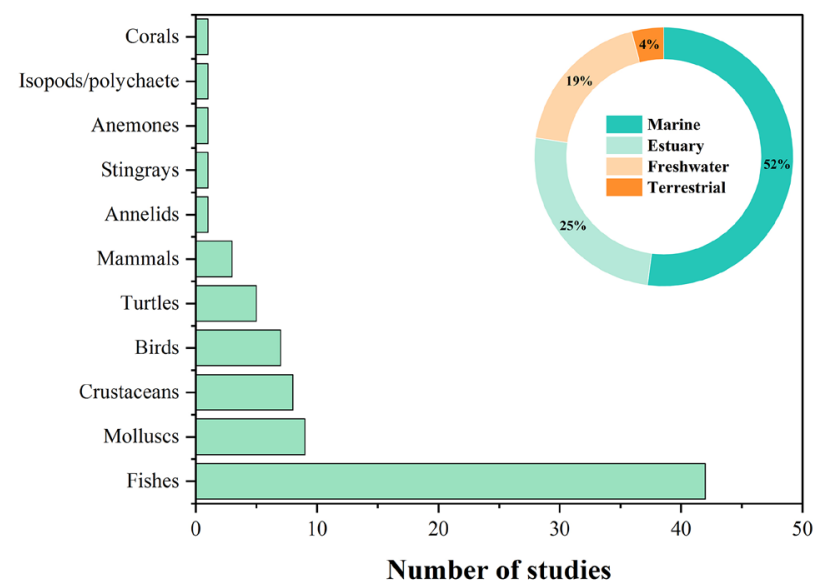

Figure 4. The number of specimens investigated in the literature reviewed. The studies were classified as either marine, estuary, freshwater, or terrestrial.

The literature reports that after collection and before the analyses in the laboratory, living organisms should be frozen or refrigerated at $-20^{\circ} \mathrm{C}$, desiccated, or preserved in fixatives such as formalin, ethanol, or formaldehyde. ${ }^{32,45}$ These processes are recommended since defecation might occur from $30 \mathrm{~min}$ to $150 \mathrm{~h}$ after catching. The excretion might eliminate the particles, leading to underestimating microplastic amounts into the studied organism. Therefore, the time between sampling, preservation, and analysis must be as short as possible..$^{54}$ In the reviewed studies, $62 \%$ of the articles had mentioned refrigeration, desiccation, or fixation of the organisms after sampling. All the studies have mentioned the part of the exanimate individual, where $48 \%$ of the studies investigated the gastrointestinal tract, and $25 \%$ exanimated the stomach.

\subsection{Sample processing of microplastics}

Filtering or sieving enables microplastics to be separated and/or fractionated from environmental matrices. The choice of pore or mesh determines the size range of microplastics that will be detected in the sample. Sieving is also used as a pre-treatment to reduce sample volume. ${ }^{47}$ In the studies reviewed, the mesh size used to sieve water samples were mainly within the range of $25 \mu \mathrm{m}$ to $5 \mathrm{~mm}$. In addition, the pore size used in the filtration process was in the range of $0.02 \mu \mathrm{m}$ to $8 \mu \mathrm{m}$. Sediment and soils samples 
often used a sieve with a mesh size of $63 \mu \mathrm{m}$ to $5 \mathrm{~mm}$ and filtration in the range of $0.45 \mu \mathrm{m}$ to $8 \mu \mathrm{m}$.

Digestion is a crucial process in environmental samples since it is responsible for reducing and eliminating organic matter and biological material, which might cause overestimation and/or underestimation of the microplastics concentration. Likewise, the use of a digestion step is highly recommended when the microplastics identification is mainly performed by visual inspection. In the studies under review, the digestion methods most used were oxidative and alkaline, although acid and enzymatic digestions were also employed. A digestion process was conducted in $48 \%$ of the surface water samples (Figure 5). The most frequently used solutions were $\mathrm{H}_{2} \mathrm{O}_{2} 30 \%$ and $\mathrm{KOH} 15 \%$. The digestion time ranged from $1 \mathrm{~min}$ to $72 \mathrm{~h}$. Heating was usually employed during digestion with temperatures in the range of 40 to $75{ }^{\circ} \mathrm{C}$. Montecinos et al..$^{55}$ submitted the samples to different processing procedures. Procedure A employed only evaporation to concentrate the sample, and procedure $\mathrm{B}$ was based upon oxidative digestion to eliminate the organic matter. According to the study, organic material was not detected in the sample submitted to digestion, which significantly facilitates the quantification and characterization of the microplastics. On the other hand, the sample subjected to procedure A had a large amount of adhered organic material, which makes it challenging to quantify and characterize microplastics. These aspects show the importance of carrying out the digestion when environmental matrices are considered.

A digestion procedure was conducted in $24 \%$ of the studies for sediment samples. The oxidation procedure was most used (81\%) with $\mathrm{H}_{2} \mathrm{O}_{2} 30 \%$ as a digestion reagent (Figure 5). Studies that performed determination

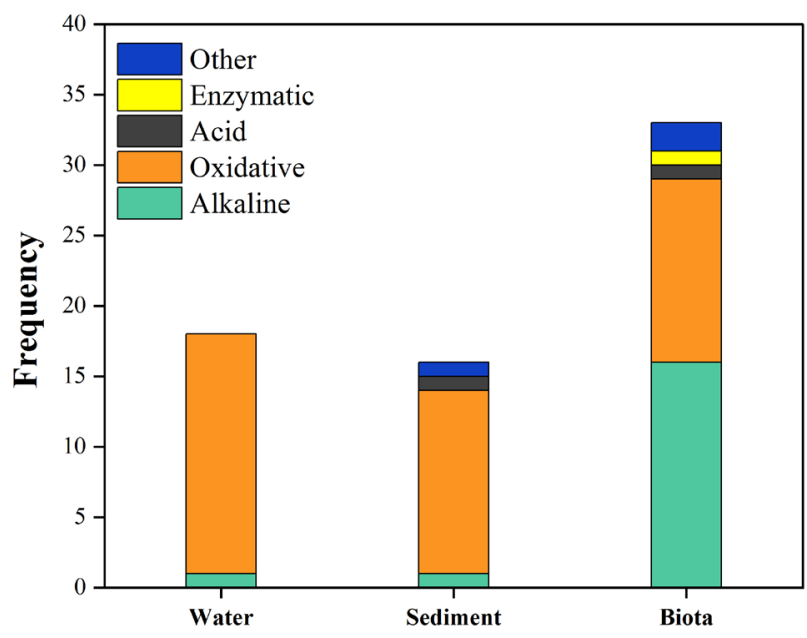

Figure 5. The digestion methods used in the different compartments among the studies under review. The "other" category refers to studies that tested two digestion processes. of microplastics in sediments from the marine environment did not conduct digestion processes in the samples. ${ }^{56-60}$

For the determination of microplastics in biota samples, the digestion step was conducted in $43 \%$ of the studies. The methods most used in biota samples were based on alkaline (47\%) and oxidizing procedures (41\%). Other procedures used $\mathrm{HNO}_{3} 65 \%$ (3\%), and enzymatic digestions (3\%) (Figure 5). Fernández Severini et al.$^{61}$ conducted a digestion process employing $\mathrm{KOH} 10 \%$ during $48 \mathrm{~h}$ for a group of samples and $\mathrm{H}_{2} \mathrm{O}_{2}$ during $72 \mathrm{~h}$ for another group. The treatment with $\mathrm{KOH}$ resulted in a higher average abundance of microplastics when compared to the one using $\mathrm{H}_{2} \mathrm{O}_{2}$. Digestion with $\mathrm{KOH}$ is already mentioned as an effective method to eliminate organic matter from biota samples, leading to a better sample clean-up, improving the identification of microplastics. ${ }^{62,63}$ The digestion with $\mathrm{H}_{2} \mathrm{O}_{2}$ is not usually recommended to treat biota samples, according to the literature, ${ }^{64}$ since this method is not effective to remove biological material from biota samples. Another study $^{65}$ employed two different digestion processes in the samples, one with $\mathrm{HNO}_{3}$ for $12 \mathrm{~h}$ and the other with $\mathrm{H}_{2} \mathrm{O}_{2}$ for 7 days, in which more complete digestion was observed in the group of samples treated with acid.

The period of treatment varies highly depending on the digestion process. Alkaline digestion is usually carried out during a period between 24 to $48 \mathrm{~h}$. The oxidative process was frequently conducted up to the final digestion. Acid treatment had the shortest time of digestion, varying between 15 to $30 \mathrm{~min}$. The only study that had employed enzyme digestion carried out the treatment during $3 \mathrm{~h}^{66}$ Additionally, the heating temperature usually employed in the digestion processes ranged from 40 to $80{ }^{\circ} \mathrm{C}$.

Density separation is usually done with $\mathrm{NaCl}$ with different densities. The large use of this salt is due to its low toxicity to nature and humans, its inexpensiveness, as well as high availability. Although, if possible, an experiment to evaluate the efficiency of separation should be performed to guarantee the split-up of the denser polymer such as polyvinyl chloride (PVC) and polyethylene terephthalate (PET). Silva and Nanny ${ }^{67}$ experimented to evaluate the density separation efficiency with sodium chloride solution $1.2 \mathrm{~g} \mathrm{~cm}^{-3}$ in different polymers. In their study, the efficiency for low-density microplastics (polystyrene (PS), polyethylene (PE), and polypropylene (PP)) was $93 \%$ while for high-density microplastics (PVC and PET) was 79\%. Therefore, other salts might be used such as zinc chloride $\left(\mathrm{ZnCl}_{2}\right)$ and sodium iodide $(\mathrm{NaI})$ with densities of 1.4-1.6 and $1.6-1.8 \mathrm{~g} \mathrm{~cm}^{-3}$, respectively. ${ }^{47}$

In water samples, flotation was used in $30 \%$ of the studies where $\mathrm{NaCl}$ was the most commonly used solution 
(92\%) followed by NaI (8\%). For sediment samples, 68\% of the studies under review used the flotation process, in which $\mathrm{NaCl}$ was most of the saturated solution employed in $54 \%$ of the studies, followed by $\mathrm{ZnCl}_{2}(17 \%)$ and marine water $(13 \%)$. Three other studies conducted flotation with calcium chloride $\left(\mathrm{CaCl}_{2}\right)$, hexametaphosphate, or water. Another study ${ }^{68}$ conducted microplastics extraction from soil with density separation in three steps. First, with water, then with $\mathrm{NaCl}$, and finally with $\mathrm{ZnCl}_{2}$. Density separation in biota samples was performed only in $8 \%$ of all the studies, where the reagents used were $\mathrm{NaCl}$, magnesium chloride, and water.

\subsection{Characterization of microplastics}

Among all the reviewed studies from Latin America, visual inspection using a stereoscope/microscope or with the naked eye is the most common technique for microplastics characterization and quantification in the environmental matrices. However, visual inspection has accuracy limitations which depend on the experience of the examiner, resolution of microscope equipment, and mainly by the clean-up of the filter (i.e., a large amount of organic matter, inorganic material, or biological tissue could difficult the identification), which may lead to either over or underestimations of microplastics abundance in the sample. ${ }^{69,70}$ Therefore, for those particles that have been identified as microplastics by visual inspection, chemical characterization to confirm their polymeric composition is highly recommended.

Microplastics were commonly classified by color, shape, and size. Color information of microplastics is a powerful tool that might provide evidence about their origin and source..$^{71,72}$ Color data was recorded in $67 \%$ of all reviewed studies, where the most common colors observed among all the matrices white/transparent and blue, with 38 and 33\% of frequency, respectively. In water and biota samples, blue was the most frequent color cited in the studies, with 46 and $42 \%$, respectively. On the other hand, in sediment samples white/transparent were predominant in $61 \%$ of the studies while blue was recorded in $15 \%$ of them as the most abundant color. The authors mentioned that a reason for the predominance of these colors is because blue and white/transparent are employed in several items and objects (e.g., jeans, fishing activities, plastic bags, bottles, cups, etc.). ${ }^{73,74}$

In biota samples, the authors suggested that the ingestion of blue particles might be explained by the selection of some species to colored microplastics since they can assume that these particles are prey or food. ${ }^{75,76}$ In addition, it is mentioned in the literature that colored microplastics are more visually attractive than fading particles. ${ }^{77,78}$ Ríos et al. ${ }^{79}$ investigated the presence of microplastics in water and fishes finding that white/transparent particles were the prevalent colors of both water and fish. According to the reviewed articles, it is observed that there is a pattern of microplastics colors ingested by biota and those found in water matrices. Blue and white/transparent were the most colors found in water and sediment samples, as shown in Figure 6, thus they may be more available and susceptible to be ingested by biota. This fact may explain why the same colors were more frequently recorded in the biota samples among the reviewed studies.

The shapes of microplastics were described in $89 \%$, in which fibers, fragments, and pellets were the most observed microplastics. Among the investigations, fibers were the most frequent shape, reported in $49 \%$ of all the studies, followed by fragment with $34 \%$, and pellet with $13 \%$. Nonetheless, other shapes such as films, filament, and foam were reported as common shapes as well. In water matrices (Figure 6), fibers account for $50 \%$ of the studies, followed by fragments $47 \%$, and films $3 \%$. In this matrix, fibers had predominance in samples collected in marine and estuarine regions. ${ }^{53,57,58}$ In biota, fibers and filaments were present in the majority proportion of the studies (64\%). Other commonly observed shapes in biota samples were fragments (23\%), and pellets (12\%), and only $1 \%$ of the studies show the predominance by filmlike microplastics. ${ }^{80}$ For instance, fish species from estuary regions of Brazil presented fibers as the predominant shape ingested, with $90 \%$ of all detected microplastics. ${ }^{81}$ These results indicate that fibers have higher bioavailability than other shapes. In literature, a possible source of fibers in the marine environment is related to the discharge of sewage without proper treatment, since fibers are mainly derived from household washings. ${ }^{67,81,82}$

On the contrary, as observed in Figure 6, fragments were the most frequent shape found in sediment samples (39\%), followed by fibers (34\%) and pellets (21\%). Among all the investigations carried out on the beaches along with Latin America, fragments and pellets were the most common shape found. For example, on the beaches of Fernando de Noronha, pellets represented $60 \%$ of all the items found. ${ }^{83}$ Sand samples collected from Boa Viagem beach also show the prevalence of small fragments. ${ }^{37}$ Sediment samples sampling from Todos os Santos Bay presented a predominance of the fragments $(70 \pm 19 \%)$, followed by fibers $(28 \pm 18 \%) .{ }^{56}$ Studies $^{84}$ have also reported the predominance of fragments in sediment samples of stormwater detention reservoirs, where fragments represent $57 \%$ of all the microplastics detected. Fragments of microplastics are mainly originated by fragmentation 
(a)
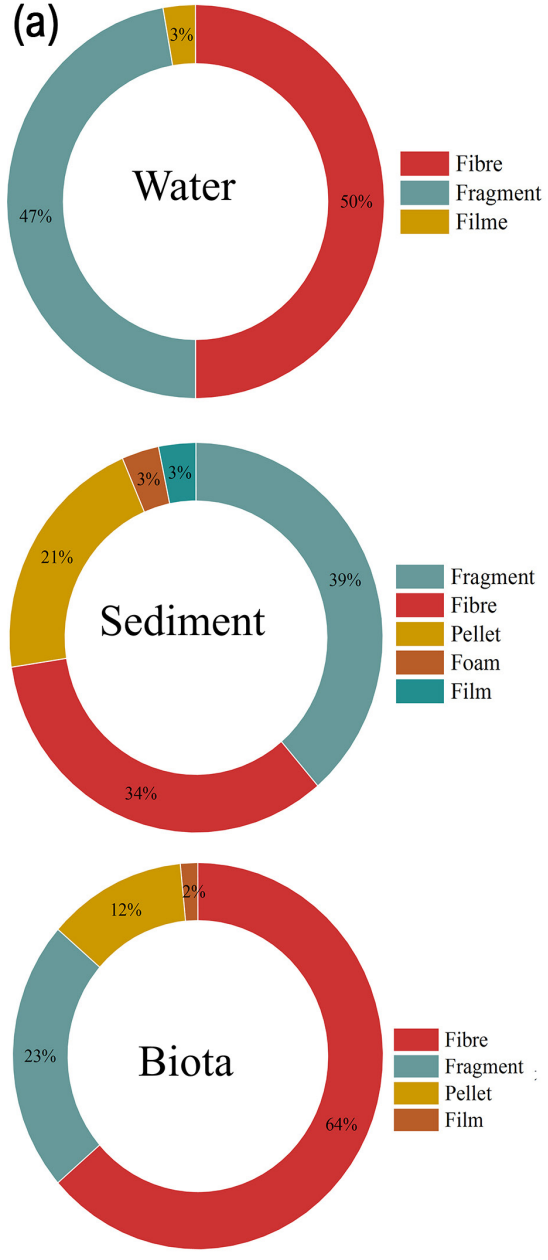
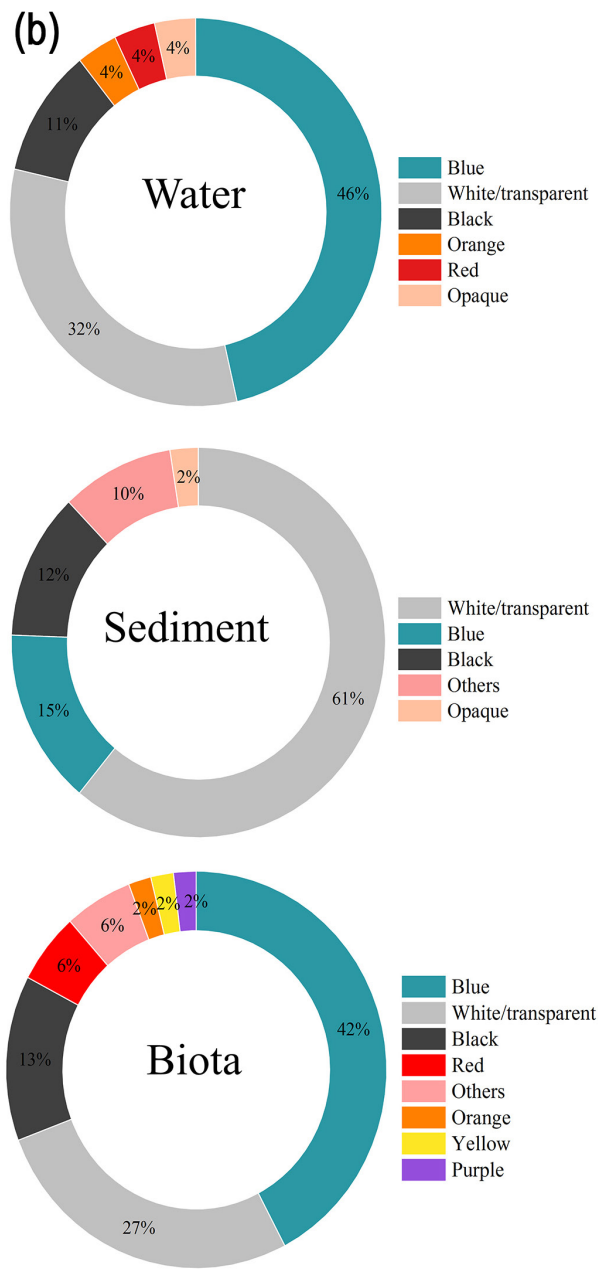

Figure 6. Percentage of predominant (a) shapes and (b) colors of microplastics recorded in the reviewed studies on the different matrices.

and degradation of large plastic items present in the environment. Acosta-Coley et al..$^{85}$ show that many pellets recovered from Caribbean beaches were fragile and had lost their physical integrity, degrading into other tiny particles. The presence of pellets in environmental samples is usually correlated with spilled during transportation or from washings of plastics factories.

The size of microplastics was recorded in 98 studies (53\%) of the 184 that performed microplastics determination. Among the studies, the size range of microplastics used was from 0.001 to $5 \mathrm{~mm}$, which is a well-described definition in the literature. ${ }^{9,10}$ Microplastics were categorized into different size fractions which were difficult for the standard characterization. In several studies, microplastic in the size class $<1 \mathrm{~mm}$ was the most abundant (48\%). For example, in the Jurujuba Cove, the microplastics collected from the water were classified into four classes: $\geq 5 \mathrm{~mm}$; $3 \leq-<5 \mathrm{~mm} ; 1 \leq-<3 \mathrm{~mm}$ and $<1 \mathrm{~mm}$, where the majority size of microplastics was $<1 \mathrm{~mm} .{ }^{86}$ Microplastics found in mussels were classified in the size range $<5 \mathrm{~mm}$ of length and estimated that the most frequent microplastics category were $>500 \leq 1000 \mu \mathrm{m} .{ }^{44}$ Microplastics separated in sediment samples from a stormwater detention reservoir were classified into three size classes $<0.5 \mathrm{~mm}, 0.5-1 \mathrm{~mm}$, and $>1 \mathrm{~mm}$ where the size class $<0.5 \mathrm{~mm}$ was the largest proportion. ${ }^{87}$

In the literature, there is also the definition of large microplastics (range 1-5 mm) and small microplastics $(<1 \mathrm{~mm}) .{ }^{88}$ In this review, large microplastics were commonly detected in biota samples..$^{80,89,90}$ For instance, large microplastics in the range of 3.2-5.3 mm were found in seabirds from along the coast of southern Brazil. ${ }^{91}$ Another study ${ }^{73}$ recorded microplastics in annelids from Estaleiro beach and described fibers varying in length from 2 to $4 \mathrm{~mm}$. In addition to these studies, large microplastics were predominant in octopods from the Mexican South Pacific. The study recorded fibers in five different fractions: $<0.25$, $0.25-0.50,0.60-1.00,1.10-5.0,>5.0 \mathrm{~mm}$ where the most predominant class was of $1.1-5 \mathrm{~mm}$ (ca. $60 \%$ of the total).$^{90}$

Chemical characterization is often performed with vibrational techniques, such as Fourier-transform infrared spectroscopy (FTIR) and Raman spectroscopy. 
Both techniques can be used with their microscopic versions (i.e., coupled with a microscope, $\mu$ FTIR or $\mu$ Raman $)^{92,93}$ In addition, recent studies ${ }^{94}$ have employed these techniques with their imaging version to improve the characterization and collect more information about microplastics particles. Likewise, microplastics can be also analyzed by scanning electron microscopy and energy-dispersive X-ray spectroscopy (SEM-EDS) once this technique could be suitable to determine surface morphology and elemental composition of microplastic particles. ${ }^{93}$ Additional methods such as pyrolysis-gas chromatography-mass spectrometry (Pyro-GC-MS) have also been used. ${ }^{93,95}$

A total of 81 reviewed studies (44\%) employed instrumental analysis to identify the polymeric composition of microplastics. FTIR technique was used in $89 \%$ of the studies, followed by Raman, which was used in $10 \%$, and SEM-EDS $1 \%$. The most frequent polymer types detected in the samples mainly include PE (44\%), PP (17\%), and PET (10\%) (Figure 7). The high frequency of these polymers in the environment agrees with the high global production of products based on PE, PP, and PET. PE and $\mathrm{PP}$ are the most polymer produced in the world, which is employed in many industry sectors, such as food packing, plastic cups, containers, agricultural films, and pipes, while PET is usually used in water, juice, and cleaner bottles. ${ }^{4}$ Other well-known polymers as PS, PVC, polyamide (PA), polyurethane (PU), polyethersulfone (PES), polysulfone (PSU), expandable polystyrene (EPS), acrylonitrile butadiene styrene (ABS), and isotactic polypropylene (IPP) have also been identified.

$\mathrm{PE}$ and PP were the most common polymer found in sand beach and water samples among the studies under

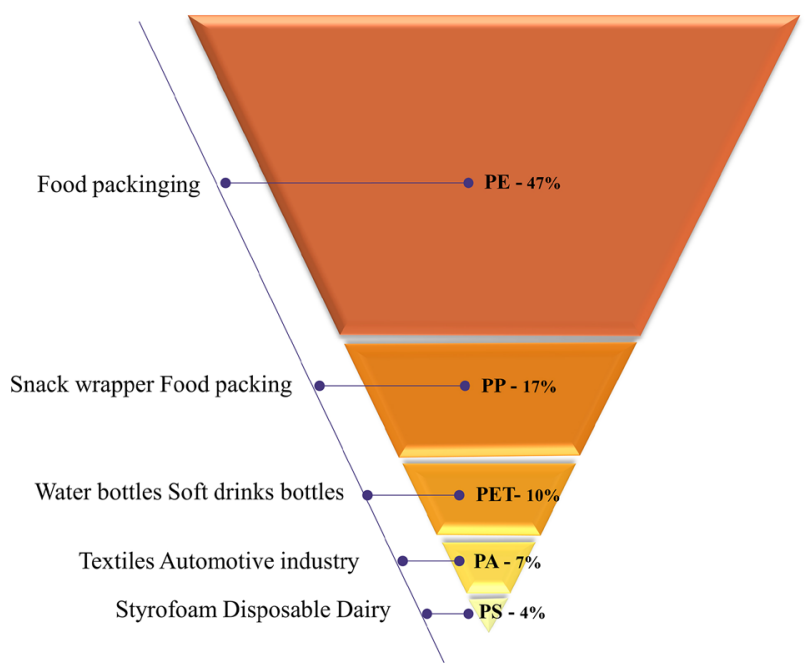

Figure 7. The most frequent polymers were reported as dominant in the studies that performed chemical characterization. The mentioned examples in the figure demonstrated the common use of each polymer in society. review. These polymers have low density and tend to float in the water surface, therefore, on the sea these particles might be carried by the tide up to the beach. In addition, most of the studies that carried out quantification of microplastics in water bodies used surface sampling methodologies, which implies only collecting less dense polymers that float on the water surface. This fact might explain the predominance of $\mathrm{PE}$ and $\mathrm{PP}$ in these samples. For instance, in water samples from Jurujuba Cove, only PE and PP accounted for 72 and $26 \%$ of all the characterized microplastics, respectively. ${ }^{86}$ In a stormwater runoff from Tijuana, the main polymer identified was PE, comprising a total of $45.2 \%$ of all the microplastics analyzed. ${ }^{96}$ In sand beach samples from Lima in Peru, microplastics were predominantly characterized as PE, IPP, and PS. The absence of PVC and PET was attributed to their high densities since these polymers tend to settle on the seafloor and did not be transported by the tide until the beaches. ${ }^{75}$ In bottom sediment samples, polymer type was identified in a few studies, ${ }^{67,97-99}$ where the frequent polymers mentioned were PP and PE. Thus, due to the lack of polymer type characterization, it was not possible to observe a pattern or the predominance of denser polymers in bottom sediment samples.

The chemical composition of microplastics was more variable in biota samples than in water and sediment matrices. For example, in fishes collected from the Amazon River of Xingu, the types of microplastics were variable, where 12 polymer types were detected, in which the majority were PE (27\%), PVC (13\%), PA (13\%), and PP $(13 \%) .{ }^{76}$ In Paraná River, the common polymer ingested by collected fishes were PE, PP, PS, and EPS. ${ }^{80}$ In the Western Atlantic Ocean in Brazil, a total of six types of polymer were identified in Longnose stingrays, where the most frequent polymer was PET (35\%), followed by PA, ABS, PE. ${ }^{100}$ Therefore, it was not possible to identify a clear correlation between the variability of the polymer type between the evaluated matrices (water, sediment, and biota). This fact highlights the need for further studies to improve the knowledge and the understanding of the predominant polymer composition of microplastics present in different environmental matrices.

\section{Microplastics Abundance}

\subsection{Abundance of microplastics in water}

Among the reviewed studies in Latin America, 41 conducted microplastics quantification in environmental matrices (22\% of the 184 studies). Summarized information of the studies is described in and Table S1 (Supplementary Information (SI) section). The publications regarding 
microplastics in water are spread among seven Latin's countries: Brazil (29\%), Argentina (27\%), Mexico (15\%), Colombia (10\%), Chile (7\%), Equator (7\%), Jamaica (2\%), and Costa Rica (2\%). As already mentioned, the content of microplastics in water bodies was majority performed in the marine environment (51\%), estuarine regions (29\%), and only a few investigations were conducted in freshwater systems (20\%). Considering these numbers, there is not enough available data for several freshwater systems in Latin America, since this region has $26.84 \%$ of the total surface freshwater in the world. ${ }^{101}$

Among the studies on microplastics in marine water, the average microplastics abundance ranged from 0.009 to 56.33 items $\mathrm{m}^{-3}$ in samples collected with nets. Figure 8 shows the distribution of 27 studies that collected water with nets and presented the concentration of microplastics in the unit of items $\mathrm{m}^{-3}$, in which it is possible to observe that more studies are needed in estuary and freshwater to conduct a better comparison. The four highest concentrations of microplastics were recorded in Brazilian territorial, in Rio de Janeiro. Castro et al. ${ }^{35,86}$ performed investigations regarding microplastics content in Guanabara Bay, where the first study found a concentration of microplastics of 16.4 items $\mathrm{m}^{-3}$ and in the second study ranged from 1.01 to 56.33 items $\mathrm{m}^{-3}$, showing a trend of increase in microplastics pollution in that region after 6 years. The other two studies ${ }^{46,102}$ found a content of microplastics of 1.40 to 21.3 items $\mathrm{m}^{-3}$ and 0.6 to 11 items $\mathrm{m}^{-3}$. The authors mentioned that this value of contamination put the region among the most contaminated coastal systems worldwide by microplastics. In addition, the high level of pollution in Guanabara Bay was associated with the disposal of

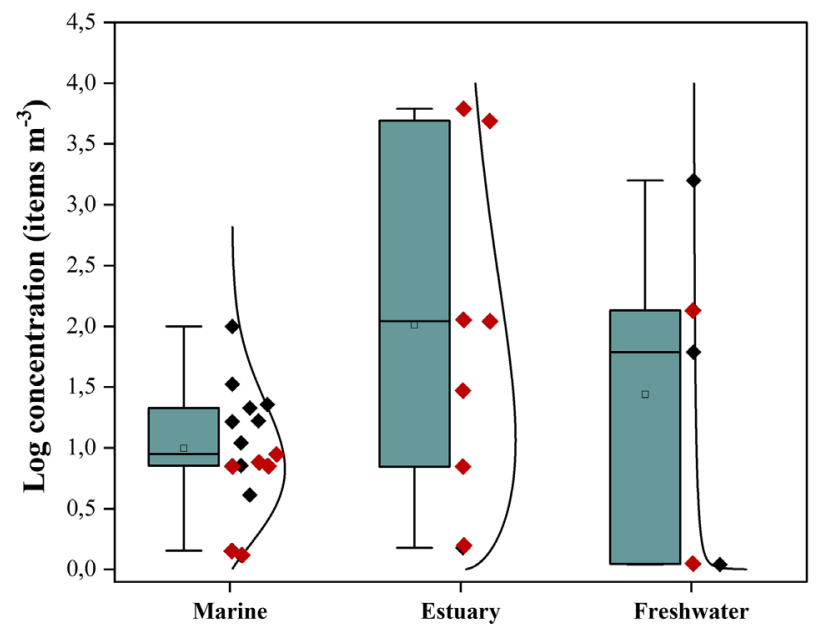

Figure 8. Box normal plot with Weibull density distribution curve regarding the concentration of microplastics in water collected with nets among marine, estuary, and freshwater environments for 27 studies. These studies show the logarithmic concentration of microplastics in terms of items $\mathrm{m}^{-3}$ which allows the comparison between different investigations. The red dots refer to studies that perform QA/QC procedures. effluents in the bay, since the sampling points were located near the channels that receive domestic effluents. These microplastics contamination data are consistent with a scenario of high population density and lack of proper sanitation and adequate solid waste management in the surrounding of Guanabara Bay. ${ }^{103}$

On the other hand, the lowest concentration of microplastics (0.009 items $\mathrm{m}^{-3}$ ) was found in the Caribbean Sea, located about $37 \mathrm{~km}$ southwest of San Andrés Island, the largest island within the reserve, and $190 \mathrm{~km}$ of the Nicaragua coast, an unpopulated area, since some regions are restricted to human activities, and therefore microplastics contamination is expected to be lower. In this area, the occurrence of microplastics was related due to the transport of these particles by wind and sea currents. ${ }^{104}$ A study carried out in the São Pedro and São Paulo Archipelago in the Equatorial Atlantic Ocean, which is located about $1500 \mathrm{~km}$ from the Brazilian coast, also quantified a low level of microplastic contamination $\left(0.03\right.$ items $\left.\mathrm{m}^{-3}\right)$ where it was hypothesized that the longdistance from the coast can result in less contamination by plastic particles. ${ }^{97}$ Other studies ${ }^{105}$ performed in Island of the Atlantic Ocean, Fernando de Noronha, Abrolhos, and Trindade, with a distance from the coast around 70 to $1200 \mathrm{~km}$, also found a low abundance of microplastics with an average of 0.03 item $\mathrm{m}^{-3}$. Lastly, a study performed in surface water from the Argentinean continental shelf and marine protected area found an abundance of microplastics around $0.06 \pm 0.008$ items $\mathrm{m}^{-3}$ which shows the importance of projects regarding the protection and conservation of marine species. ${ }^{57}$ These studies show that the high population density and the absence of proper collection of domestic wastewater and management of solid waste might cause the entry of microplastics and plastic materials into the marine environment. Ríos et al. ${ }^{79}$ collected samples using a Niskin bottle and found a concentration of microplastics of 10,500 items $\mathrm{m}^{-3}$, although this content of microplastics has been the highest among the marine samples, the comparison with other studies which employ different sampling methods (i.e., net sampling) is not recommended. Therefore, regarding the studies of microplastics contamination in marine waters of Latin America, it was possible to observe a trend of higher contamination levels by microplastics in locations nearshore. Since, among 13 studies that performed microplastics investigation in marine water with trawls, all the studies which sampled water offshore demonstrated a lower level of microplastics $\left(<0.2\right.$ items $\left.\mathrm{m}^{-3}\right)$ when compared with samples nearshore.

The abundance of microplastics in estuary regions varied from 0.1 to 782,000 items $\mathrm{m}^{-3}$. The substantial difference 
in the range of microplastics concentration might be due to the different sampling methods. Forero López et al. ${ }^{106}$ collected samples with bottles in Bahía Blanca Estuary and found an expressive amount of microplastics in the range

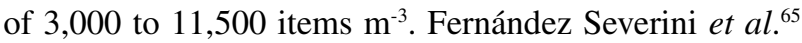
sampled water from Bahía Blanca Estuary and found a concentration of microplastics ranged from 5900 to 782,000 items $\mathrm{m}^{-3}$ in water collected with Van Dorn bottle and 42.6 to 113.6 items $\mathrm{m}^{-3}$ in sampling with plankton net $(60 \mu \mathrm{m})$. Pazos et al ${ }^{107}$ sampled water with a bucket in the estuarine region of Rio de la Plata, Argentina, and found a

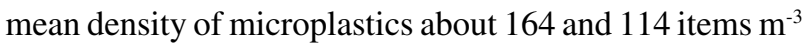
where the higher density of plastic particles was associated with the proximity to cities highly populated. The lower concentration of microplastics content collected from estuarine regions was found in the Martínez-Baker Channels in Chilean Patagonia ( 0.1 to 7 items $\left.\mathrm{m}^{-3}\right){ }^{108}$

Concerning microplastics contamination in freshwater systems the concentration ranged from 0.91 to $23.6 \times 10^{6}$ items $\mathrm{m}^{-3}$. It is important to highlight that the highest levels of microplastics contamination were reported in studies where samplings were performed with bucket and bottle. ${ }^{55,109}$ Montecinos et al..$^{55}$ sampled water from a stream in Argentina and found a high quantity of microplastics, around $23.6 \times 10^{6}$ items $\mathrm{m}^{-3}$. The massive concentration in that study was related to the low flow of water in the Langueyú stream, thus microplastics could accumulate in the channel receiving wastewater of an intermediate city. Ferraz et al. ${ }^{109}$ collected water samples from Sinos River, Brazil, where found microplastic concentrations in the range of 330,000 to 940,000 items $\mathrm{m}^{-3}$ which were associated with the discharge of sewage from sinks and washing machines once the municipality treats less than $10 \%$ of the total generated sewage.

On the contrary, studies conducted with trawls show comparable results in order of magnitude. The studies performed by Bertoldi et al. ${ }^{110}$ in Lake Guaíba, Brazil, also associated the level of microplastics contamination with the level of population density, and an average from $11.9 \pm 0.6$ to $61.2 \pm 6.1$ items $\mathrm{m}^{-3}$ was found. The study also highlights the influence of geohydrological characteristics of the lake, which might influence the distribution of microplastics in the water. On the other hand, the lower microplastics concentration was found in Lakes from Patagonia, Argentina $\left(0.9 \pm 0.6\right.$ items $\left.^{-3}\right)$ and in the Atrato Delta, Colombia $\left(0.91\right.$ items $\left.\mathrm{m}^{-3}\right){ }^{111,112}$

The microplastics contamination in water bodies is widely studied worldwide and it is strongly variable since it depends on several facts mentioned above. For instance, Zhang et al., ${ }^{113}$ collected marine surface water from the South of China with a water collector of $5 \mathrm{~L}$ and the mean abundance of microplastics was 8895 items $\mathrm{m}^{-3}$. Kashiwabara et al. ${ }^{114}$ sampled surface waters of Monterey Bay with net tows and found the mean concentration of particles to be $1.32 \pm 0.70$ items $\mathrm{m}^{-3}$, in which they mentioned that microplastics abundance was lower offshore than in sampling sites collected to nearshore sites. This study agrees with the studies that collected marine surface water in Latin America, where studies from offshore samples showed a lower level of microplastic contamination than nearshore regions. Jian et al. ${ }^{115}$ collected samples in the Poyang Lake and its tributaries, where the concentration of microplastics varied greatly in the range from $35 \pm 5$ to $1064 \pm 90$ items $\mathrm{m}^{-3}$, in which was observed lower contamination by plastic particles into the Natural Reserve sites, once inside de reserve the human activities is restricted. By comparing the reported microplastics abundance in water bodies between Latin American countries and countries worldwide, it was observed that some regions have similar content of microplastics contamination. Hence, the microplastics abundance in water compartments varied greatly among the reviewed studies, mainly due to the difference of methods used to sampling water, the type of water body (marine, estuary, and freshwater), and the localization of the sampling (i.e., regions with high population density are more susceptible to have higher microplastics contamination).

\subsection{Abundance of microplastics in sediment/soil}

From the 68 studies regarding the quantification of microplastics in sediment/soil samples, 49 informed the abundance of microplastics contamination. The studies are distributed in 12 Latin America countries: Brazil (33\%), Mexico (20\%), Argentina (12\%), Colombia (10\%), Chile (6\%), Uruguay (4\%), Ecuador (4\%), Peru (2\%), Puerto Rico (2\%), Panama (2\%), Guatemala (2\%) and Lesser Antilles (2\%). The widespread microplastics contamination in sediment and soil samples is evidenced by its presence in both terrestrial and aquatic compartments. Microplastics in beach sediments accounted for $53 \%$ of the studies, followed by bottom marine sediments (18\%), soil samples (14\%), freshwater sediments (12\%), and estuary sediments (4\%). The overview of microplastics abundance in Latin American sediment/soil is summarized in Table S2, SI section. Furthermore, Figure 9 shows the distribution of 23 studies that collected sediment and soil, which presented the concentration of microplastics in the unit of items $\mathrm{kg}^{-1}$, where there was a great variation in the concentration of microplastics among the different studied environments.

The distribution of microplastics in beach sediments

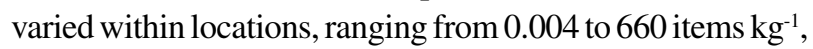




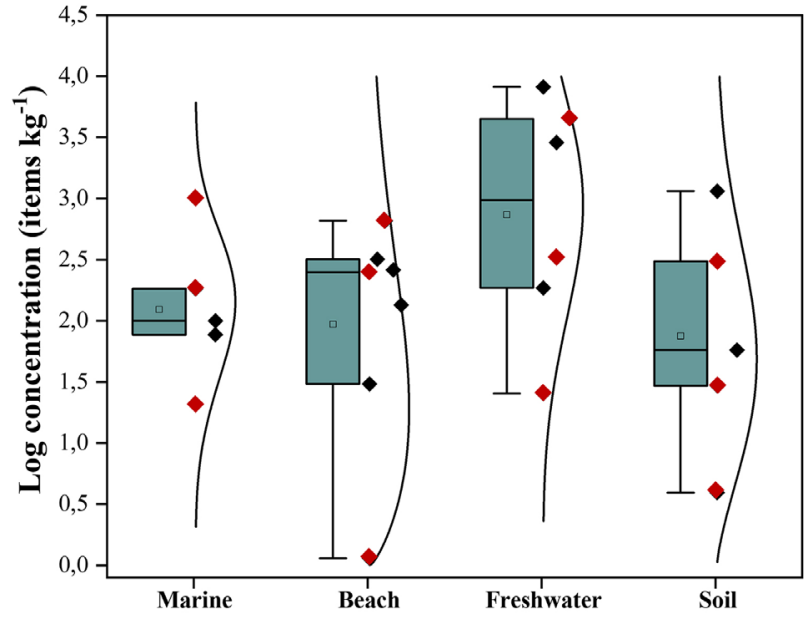

Figure 9. Box normal plot with Weibull density distribution curve regarding the concentration of microplastics in sediment (marine, beach and freshwater), and soil environments for 23 studies. These studies show the logarithmic concentration of microplastics in terms of items $\mathrm{kg}^{-1}$ which allows the comparison between different investigations. The red dots refer to studies that perform QA/QC procedures.

0.000029 to 88,224 items $\mathrm{m}^{-2}$ and 5.9 to 530 items $\mathrm{m}^{-3}$. The lower microplastics abundances $\left(<10\right.$ items $\left.\mathrm{m}^{-2}\right)$ were found in Boa Viagem (0.000029 items $\left.\mathrm{m}^{-2}\right)$, Córdoba $\left(4\right.$ items $\left.\mathrm{m}^{-2}\right)$, Chocolate (3 items $\mathrm{m}^{-2}$ ), Tumaco Bay $\left(4\right.$ items $\mathrm{m}^{-2}$ ), and Viuda (0.6 items $\mathrm{m}^{-2}$ ) beaches located in Brazil, Colombia, and Uruguay. ${ }^{37,88,116}$ On the other hand, the most polluted sites were situated in Argentina, Colombia, Brazil, México, and Peru with abundances reaching more than 500 items $\mathrm{m}^{-2}$. A wide range of microplastics contamination was found on sandy beaches of Guanabara bay (12 to 1300 items $\mathrm{m}^{-2}$ ), and Cartagena beach (249 to 1387 items $\mathrm{m}^{-2}$ ) which is probably related to inadequate waste management, high rates of recreational tourism and industrial, and fishing activities. ${ }^{116,117}$ The most polluted site was reported by Mitchell et al., ${ }^{118}$ in Argentina, with up to 88,224 items $\mathrm{m}^{-2}$, the authors found that the sites closer to higher anthropogenic activities presented higher concentrations of microplastics, evidencing the contribution of the population to plastic pollution.

In soil samples, microplastics have been reported within extremely variable abundances, from 184 to 57,542 items $\mathrm{kg}^{-1}$. The lower abundances were found in Chile and Mexico with less than 1,000 items kg-1 of soil. ${ }^{119,120}$ Corradini et al. ${ }^{120}$ found the lowest abundance of microplastics in soils of Latin America, 184 items kg-1 and 306 items $\mathrm{kg}^{-1}$ on soils of pastures and croplands, respectively. In this study, it was found that pastures and croplands are more prone to be polluted with microplastics than rangelands with shrubs and natural grasslands. This is also supported by Álvarez-Lopeztello et al., ${ }^{121}$ who studied different types of soils samples in Mexico (rainforest, pine plantations with management and without management, natural savannas, and pastures). The highest microplastics abundance was found in the pasture soil rather than the locations with coverage, microplastics could be air-transported and accumulate in areas with less or null vegetation cover. ${ }^{121}$

On the other hand, Moruzzi et al. ${ }^{84}$ found the highest abundance of microplastics in Latin American studies. The microplastics collected in the sediments of an empty stormwater detention reservoir in Brazil contained an abundance of 57,542 items $\mathrm{kg}^{-1}$ of sediment. Values are extremely higher than the ones reported in the United States $\left(1,270\right.$ items $\left.\mathrm{kg}^{-1}\right)$ and China (2,020 items kg-1 $) .{ }^{122,123}$ The importance of detection of microplastics in soil samples is due to the adverse impact that these particles can cause on soil parameters such as the hydrodynamics of the water and the diversity and microbial activity. As a consequence, soil chemical properties (e.g., carbon, nitrogen, and phosphorus) might change affecting the soil nutrient cycle. ${ }^{121}$

Nevertheless, the occurrence of microplastics in aquatic sediments has also been recorded. Among the studies that evaluated marine sediments, microplastics were detected in a range concentration between 0.01 to 1,000 items $\mathrm{kg}^{-1}$ and 850 to 25,794 items $\mathrm{m}^{-2}$. Microplastics abundance in freshwater sediments ranged from 31 to 8,178 items $\mathrm{kg}^{-1}$ and 104 to 1,004 items $\mathrm{m}^{-2}$. Gerolin et al. ${ }^{124}$ found microplastics abundances from 417 to 8,178 item kg-1 of sediment among the seven sampled sites in the Amazon Rivers. Negro River had the highest abundance (up to 2-fold or more) of the other analyzed rivers and despite the proximity with Manaus city (anthropogenic sources), it was pointed out that the riverbed morphology and river hydraulic characteristics are factors that influenced the abundance of microplastics. The backwater effect of the Solimões River reduces the average water flow velocity in the Negro River, creating a low-energy environment, which favors the deposition of suspended particles. ${ }^{124}$

The highest level of microplastics abundance in marine sediments was found in Guanabara Bay (160-1000 items kg ${ }^{-1}$ ). ${ }^{59}$ As mentioned before, Guanabara Bay located in Rio de Janeiro is known as one of the most contaminated sites on the Brazilian coastline, which is due to the rapid development of the urban areas surrounding bay. ${ }^{117}$ Baptista Neto et al. ${ }^{60}$ found an abundance of microplastics (mainly fibers) in Vitória Bay with an average of 100 items $\mathrm{kg}^{-1}$ of bottom sediment, and possible sources are related with untreated sewage and closeness to dumping sites. In addition, Ronda et al. ${ }^{57}$ found a higher abundance of microplastics (360 items kg-1) in the offshore site closest to the cities of Pehuenco and Monte Hermoso, whereas samples sites offshore are more distant in the South Atlantic Ocean presented the lower 
concentrations of microplastics (40 items $\mathrm{kg}^{-1}$ ). This indicates that the proximity to anthropogenic sources influences the concentration of plastic particles in marine bottom sediments. Microplastics concentrations found in Latin America aquatic sediments are higher than the ones found in Indonesia (28.09 items $\mathrm{kg}^{-1}$ ), France (0.67 items $\mathrm{kg}^{-1}$ ), Black Sea (106.7 items $\mathrm{kg}^{-1}$ ), and Arabian Sea (128 items $\left.\mathrm{kg}^{-1}\right)$, and lower than the ones found in Norway $\left(200,000\right.$ items $\left.\mathrm{kg}^{-1}\right) .{ }^{125-129}$

\subsection{Abundance of microplastics in biota}

The presence of microplastics in biota might be used as an indicator of microplastics pollution among the different compartments. In Latin America, studies regarding the contamination of biota by microplastics were recorded in 75 studies, in which the presence of microplastics was commonly demonstrated in terms of concentration (items ind ${ }^{-1}$ and items $\mathrm{g}^{-1}$ ) and/or in terms of frequency occurrence of microplastics into the organism. Table S3 (SI section) presents a summary of the field studies that conducted microplastics investigations. The articles are distributed among nine countries: Brazil (56\%), Argentina (13\%), Chile (9\%), México (7\%), Peru (4\%), Uruguay (4\%), Colombia (3\%), Equator (3\%), and Costa Rica (1\%). More than half studies are focused on organisms of marine and estuary environments. Fishes were the most investigated organisms, followed by mollusks and crustaceous. Microplastics translocation within different organs was observed with the presence of these particles throughout the entire body of the studied animals. The particles were found on stomachs, guts, gills, gastrointestinal tract, and even on feces.

The uptake of microplastic particles by vertebrates has been conducted in 58 studies (77\%). The rate of contamination or the abundance of microplastics was recorded in 54 studies $(70 \%)$. The ingestion of microplastics by vertebrates might occur by two major pathways: $(i)$ microplastics could be ingested spontaneously in which plastic particles are mistaken with prey or food; (ii) microplastics could be transferred unspontaneous by the food web once the predator feeds on prey that has been already contaminated with microplastics. ${ }^{130}$ Among the studies, the frequency of occurrence regarding microplastic ingestion in vertebrates' organisms was between 2 and $100 \%$. The high prevalence of microplastics $(100 \%)$ was observed in fish species from coastlines, estuary, and freshwater of Argentina, Costa Rica, Brazil, Mexico, and in otariids from Peru and Chile. ${ }^{80,89,131-134}$ The lower frequency of microplastics (2 to $10 \%$ ) was registered in studies performed in species of fishes from the estuary, coastlines, and sea from Brazil, Chile, and Colombia and in turtles species from the coastline of Brazil. ${ }^{81,135-139}$

For vertebrates, the abundance/individual ranged from

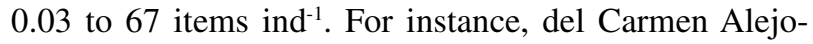
Plata, ${ }^{90}$ collected fish from the Gulf of Tehuantepec in

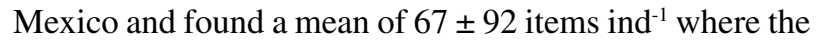
highest percentage of microplastics were detected in the stomach contents. Silva-Cavalcanti et al. ${ }^{140}$ investigated fish from a tropical freshwater of Brazil and found a total of 176 debris among all the 40 guts studied, in which the

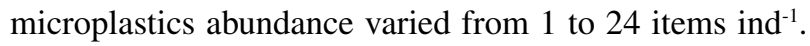
They suggest that the high incidence of microplastics by some species could be related to its feeding behavior since some individuals feed on benthic prey, thus it is likely that they might ingest plastic debris deposited on the sediment when foraging on the bottom. Another study $^{89}$ conducted a microplastics investigation in the gut content of coastal freshwater fish from Rio de la Plata, Argentina, and found an average number of microplastics

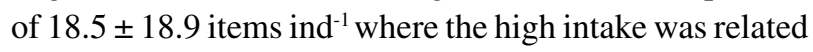
to the extensive exposure of these species to microplastics in their habitat. Lower concentrations of microplastics in vertebrates were recorded in fishes collected from different locations of the Pacific Ocean coastline in Chile, Colombia, Ecuador, Panama, and Peru in which microplastics were detected in the range of $0.03-0.1$ items ind ${ }^{-1} .{ }^{138}$ In the study of Ory et al., ${ }^{138}$ it is mentioned that in remote regions with small human populations, the incidence of plastic contamination in biota is small when compared with the sample collected close to populated areas. A study performed by Neto et al., ${ }^{36}$ also found low microplastics content in fisher from southeast-south Brazilian coast in the range of 0.06-1.65 items ind $^{-1}$.

The abundance of microplastics in biota has also been extensively reported in several studies worldwide. For instance, the abundance of microplastics in Skipjack Tuna collected on the Southern Coast of Java, Indonesia ranged from 0 to 9 items ind ${ }^{-1} \cdot{ }^{141}$ Four fish species collected in the northwestern Iberian continental shelf showed an average

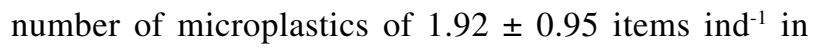

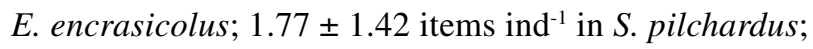
$2.53 \pm 1.88$ items ind $^{-1}$ in C. lyra and $1.56 \pm 0.53$ items ind $^{-1}$ in $M$. surmuletus, in which they observed a significant increase of the number of microplastics ingested with increasing fish. ${ }^{142}$ Besides, Weitzel et al., ${ }^{143}$ detected microplastics in two species of a resident marsh bird, Clapper Rails (Rallus crepitans) and Seaside Sparrows (Ammospiza maritima), in coastal marsh ecosystems within Mississippi, where the median count

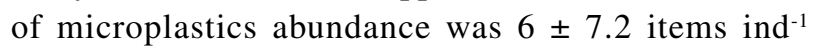




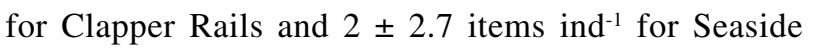
Sparrow. Microplastics were also found in blue panchax fish from Ciliwung Estuary, Jakarta, Indonesia in which the average microplastics concentration of all fish samples collected was 1.97 items ind ${ }^{-1} \cdot{ }^{144}$ Another study investigated the ingestion of microplastics in fish from the Canary Islands and among the 96 individuals studied, the average regarding the abundance of microplastics was $2.77 \pm 1.91$ items ind ${ }^{-1} .{ }^{145}$ By comparing the microplastics abundance in biota from different studies worldwide, it was found that the abundance of microplastics in biota in Latin America was, in general, at the same order of magnitude as that in other regions. Although, it is important to highlight that comparisons between regions are hindered mainly by differences in sampling techniques and identification methods.

The uptake of microplastics by invertebrates has been conducted in 18 studies (24\%), in which bivalves, crustaceous, annelids, coral, and anemone were the individuals studied. The rate of contamination or the abundance of microplastics were recorded in 13 studies (72\%). The contamination rates of the studied species were between 30 and 100\%. For example, the highest contamination rate was observed in mussels collected from Guanabara Bay, Brazil and Ushuaia Bay, Argentina, and in oysters from Bahía Blanca Estuary, Argentina. ${ }^{43,65,146}$ The abundance of microplastics in invertebrate organisms

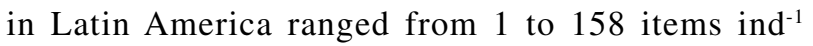
and 0.3 to 3.15 items $\mathrm{g}^{-1}$. The highest concentration of microplastics in terms of items ind $^{-1}$ were recorded in the gut contents of crabs sampled in Grussaí Beach Arch, Brazil, in which the abundance of microplastics ranged from 1 to 158 items ind ${ }^{1}$ (Figure 10). ${ }^{147}$ Likewise, high concentrations of microplastics were found in the mussels of Guanabara Bay, Brazil, which had an abundance of $31.2 \pm 17.8$ items ind $^{-1}$ where they did not find significant differences in the MP content between farmed and wild mussels. ${ }^{43}$ Regarding items/weight, the highest concentrations were observed in the bivalves of the coast of Peru where the contamination was $3.15 \pm 0.81$ items $\mathrm{g}^{-1} \cdot{ }^{148}$

The abundance of microplastics in invertebrates is commonly studied worldwide, where some groups of individuals are of particular concern such as bivalves and crustaceans since some species are for human consumption and might be a source of microplastics for human beings. For instance, the abundance of microplastics in decapod crustaceans collected on the northeast coast of Ireland

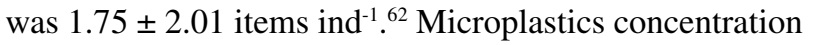
ranged from 1.7-2 items ind ${ }^{-1}$ in mussels from the Northern Ionian Sea. ${ }^{149}$ In addition, oysters and mussels collected from the Dutch coast show microplastics content from
1.9-29 items $\mathrm{g}^{-1} \cdot{ }^{150}$ In general, the average number of ingested microplastics of Latin American invertebrate's organisms are similar to studies worldwide and this fact shows the omnipresence of these particles even in different regions around the globe.

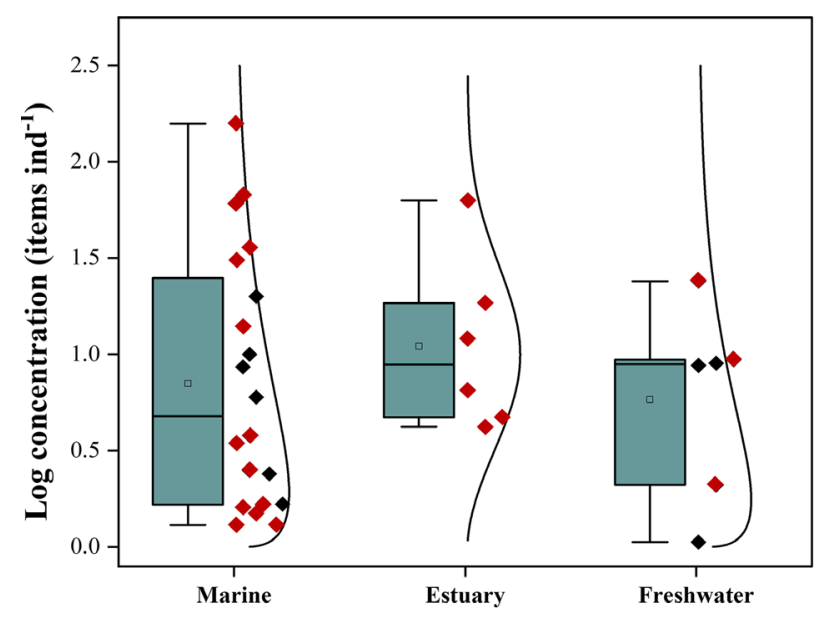

Figure 10. Box normal plot with Weibull density distribution curve regarding the concentration of microplastics in biota among marine, estuary, and freshwater environments for 32 studies. These studies show the logarithmic concentration of microplastics in terms of items ind ${ }^{-1}$ which allows the comparison between different investigations.

In summary, in terms of contamination, it has been hypothesized that marine organisms might ingest more plastics rather than species in freshwater and estuary areas. ${ }^{36}$ Therefore, to investigate this hypothesis, Figure 10 shows the maximum microplastics abundance of 30 biota studies in terms of items ind ${ }^{-1}$. It might be observed that the majority of data of marine studies were in the first quartile of the box plot which indicates that most of the studies found a low concentration of microplastics. Besides, in a general manner, plastic ingestion by organisms was higher in coastal regions once these studies are the outliers in the box plot, and agree with higher abundance of microplastics found in aquatic matrices nearshore areas, as discussed in section $4 \cdot 1 .^{78,90,133,147,151}$

\section{Presence of Contaminants in Microplastics}

Several studies had already demonstrated the combined effects of microplastics and environmental pollutants. Additives incorporated in the polymeric matrix during plastic production and/or chemicals from surrounding environments sorbed onto microplastics can be transported to long distances worsening the widespread trace pollutants and posing risk to aquatic biodiversity. A wide range of factors can influence the sorption of contaminants on microplastics, such as hydrophobicity, polarity and surface functional, polymer type, age, and color. ${ }^{152,153}$ Therefore, 
these aspects are recommended to be considered in the studies. Weathering can lead to surface modifications in microplastics particles, as an increase of surface area and pore volume in which might enhance its sorption capacity and hence promote widespread contamination of contaminants in the environment.

Among the studies under review, a total of 12 were performed across Latin America regarding plastic particles with contaminants in which were focused on Brazil $(50 \%)$, Uruguay (17\%), Mexico (17\%), Chile (8\%), and Colombia (8\%). Heavy metals were analyzed in 5 studies, where 3 determinate the concentration of metals in the plastic fragments and 2 analyzed the presence of these metals on the microplastics surface. For instance, analyzed microplastics from Brazil, Uruguay, and Mexico showed a great presence of aluminum and iron from 36 to $2,809 \mu \mathrm{g} \mathrm{g}^{-1} \cdot{ }^{88,154,155}$ These values, although variable between the sites is significantly higher when compared to the ones found in Croatia (19-88 $\mu \mathrm{g} \mathrm{g}^{-1}$ ) and England $\left(0-314 \mu \mathrm{g} \mathrm{g}^{-1}\right) .{ }^{156,157}$ The presence of metals such as Fe and $\mathrm{Al}$ can be derived from natural volcanic and geologic sources. ${ }^{154}$ On the other hand, toxic metals such as arsenic, barium, cadmium, chromium, lead, and selenic, which are among the 8 monitored metals of RCRA (Resource Conservation and Recovery Act), have been found in microplastics from Cartagena beach, Fabeiro beach and Atoyac River sediment. ${ }^{88,154,158}$ Lead was found in concentrations above $40 \mu \mathrm{g} \mathrm{g}^{-1}$ in secondary microplastics of Cartagena beach and 5,000 $\mu \mathrm{g} \mathrm{g}^{-1}$ of Fabeiro beach, and its concentration was greater compared to non-degraded pellets both in Cartagena and Fabeiro beaches, which corroborate the assumption that polymer aging might promote sorption of contaminants. These results were also observed by Vedolin et al. ${ }^{155}$ where beached microplastics presented higher concentrations of some metal species (up to two-fold or more). The possible sources of these metal contamination could be both their presence in plastic pellets due to manufacturing processes or sorption of metals already on the environment once processes derived from industries and agriculture can cause environmental contamination of these metals. ${ }^{154,157}$

In the same way, the sorption of organic pollutants on beached microplastics is being investigated around the world, where polycyclic aromatic hydrocarbons (PAH), polychlorinated biphenyls (PCB), polybrominated diethyl ethers (PBDE), and organochlorines (OC) are the most common type of contaminants detected. ${ }^{159-165}$ Among the studies performed in Latin America, PAH was detected in beached microplastics on $58 \%$ of the studies, PCB in $42 \%$, OC in $25 \%$, and PBDE of $17 \%$ studies. $\mathrm{PAH}$ was only detected in Brazilian and Uruguayan beached microplastics, within concentrations ranging from 62.1 to $39,763 \mathrm{ng} \mathrm{g}^{-1}$. Punta del Este beaches presented the narrowest range of PAH concentration (62.1 to $758 \mathrm{ng} \mathrm{g}^{-1}$ ) observed on Latin America studies, which is also lower than the ones reported in China (11.2 to $7.710 \mathrm{ng} \mathrm{g}^{-1}$ ), Canary Islands (52.1 to $\left.17,723 \mathrm{ng} \mathrm{g}^{-1}\right)$ and Portugal (53 to 44,800 $\mathrm{ng} \mathrm{g}^{-1}$ ). ${ }^{159,160,166}$ The Uruguayan studies (Punta del Este and Fabeiro beaches) had PAH distribution dominated by congeners of three and four rings (e.g., phenanthrene, anthracene, chrysene, pyrene) indicating a mix of petrogenic and pyrogenic sources. ${ }^{88,167}$ The maximum concentration of PAH in microplastics of Santos Bay was 1.4 to 52-fold higher than the highest values found in the other locations of Latin American studies. These PAH concentrations reflect the possibility of contaminated particles to be transported through environments once PAH concentration on microplastics of Santos Bay was extremely variable (130 to $\left.39,763 \mathrm{ng} \mathrm{g}^{-1}\right) .{ }^{168-171}$ This assumption is supported by the findings of Brennecke et al. ${ }^{172}$ who exposed microplastics to pre-weathering treatments in the seawater of Arraial do Cabo (location part of the Marine Harvest Reserve) and Jurujuba (location close to Guanabara Bay, a site heavily impacted by fishing industry in Brazil) and compared the concentration of phenanthrene in both water column and microplastics (after 2 weeks of exposure). Both Jurujuba and Arraial do Cabo presented microplastics with concentrations of phenanthrene like those detected in the water column. This indicates that the wide range of PAH concentrations found in microplastics of Santos Bay could be a result of the transport of contaminated particles through environments. Nevertheless, the heavy shipping traffic in Santos Harbour, together with sewage and fossilfuel combustion can be associated as possible sources of PAH in Santos Bay, which was already pointed out by other authors as sources of PAH in the environment. ${ }^{173}$

PCB was detected in Chilean, Uruguayan, and Brazilian beached microplastics, in a concentration range from 0.8 to 7,554 $\mathrm{ng} \mathrm{g}^{-1}$. Microplastics collected through the São Paulo coast in Brazil presented the widest range of PCB concentration (3.41 to $7,554 \mathrm{ng} \mathrm{g}^{-1}$ ) which is consistent with the discussion above on the possible transport of contaminated microplastics from outside areas. ${ }^{170}$ Pellets collected on Lenga beach in Chile (3.17 to $58.4 \mathrm{ng} \mathrm{g}^{-1}$ ) and Fabeiro beach in Uruguay (37.1 to $55.3 \mathrm{ng} \mathrm{g}^{-1}$ ) had PCB concentration within the range found by Gorman et al., ${ }^{152}$ in Southern Brazil ( 0.80 to $\left.104 \mathrm{ng} \mathrm{g}^{-1}\right) .^{88,152,174}$ Sources of PCB on beached pellets could be related to anthropogenic activities and sediment dredging near ports, where microplastics could interact with the dispersed PCB before reaching the shore. ${ }^{170,174} \mathrm{PBDE}$ and $\mathrm{OC}$ was detected in 
the Chilean and Brazilian coastline and OC were also reported in microplastics collected in the Uruguayan beach Fabeiro. ${ }^{88,170,174}$ PBDE concentrations in Latin American countries ( 0.05 to $\left.137 \mathrm{ng} \mathrm{g}^{-1}\right)$ were considerably lower than the ones reported in other locations (e.g., Canary Islands, 0.06 to 3,923 $\left.\mathrm{ng} \mathrm{g}^{-1}\right) .{ }^{160}$ Moreover, Chilean beached microplastics presented $\mathrm{OC}$ range concentration $(0.1$ to $\left.7 \mathrm{ng} \mathrm{g}^{-1}\right)$ lower than those reported by other countries such as Greece (18 $\mathrm{ng} \mathrm{g}^{-1}$ ) and Portugal (0.42-41 $\left.\mathrm{ng} \mathrm{g}^{-1}\right){ }^{159,162}$ On the other hand, OC found on microplastics from the São Paulo coast (12.8 to $1,048 \mathrm{ng} \mathrm{g}^{-1}$ ) and Fabeiro beach ( 1,035 to $\left.2,041 \mathrm{ng} \mathrm{g}^{-1}\right)$ was higher than the observed on those locations. ${ }^{159,162}$

\section{Microplastics Interaction with Biota and Its Toxicological Effects}

\subsection{Physical and toxicological effects}

The impacts of large plastic materials in biota are often reported and generally understood, the physical effects caused by microplastics are not visible and might pose great risks to organisms. The false satiation after the ingestion could lead to reduced energy reserves due to lower assimilation of natural prey, which might be related to the blockage of the digestive tract resulting in a reduction of animal body condition. The lower abundance of animal prey was observed in crabs from Ponta Verde beach in Brazil as well as in sandy beach amphipods fed by contaminated prey in Chile. ${ }^{175,176}$ The decrease in body condition is a consequence of the ingestion of these plastic particles and had been already linked to a decrease in the survival of juvenile seabirds, tadpoles, and langoustine around the world. ${ }^{177-179}$ In Brazil, Rossi et al. ${ }^{180}$ found plastic fragments and pellets in the stomachs of dead Haematopus palliatus shorebirds. Most of the individuals (58\%) were juveniles and the presence of hard fragments in their stomachs could indicate a limited growth and development of the specimens which could have increased the juvenile's mortality.

In the literature, under review 28 laboratory studies have been performed in Latin America to elucidate the toxicological effects induced by microplastics exposure. These effects were observed in fish (29\%), mussel (21\%), tadpoles (18\%), sea urchin (7\%), worms (7\%), crustaceans (7\%), dragonflies (4\%), mice (4\%), amphipod (4\%), copepod (4\%), oyster (4\%), coral (4\%) and nematodes $(4 \%)$. The associated toxicological effects involve the impairment in the development, locomotion activity, hepatotoxicity, genotoxicity, neurotoxicity, and cytotoxicity. A recent study ${ }^{181}$ exposed Danio rerio to microplastics and found that the plastic particles impaired embryo hatching and larval survival rate. In addition, the intake of microplastics, as it accumulates in the organism, impair the digestion, absorption, and consequently the energy supply needed for locomotion activity. Tadpoles exposed to PE microplastics had their locomotor activity affected, also impacting their predator avoidance. ${ }^{182}$ da Costa Araújo et al.$^{183}$ also found cytological and liver changes of hepatotoxicity on tadpoles. Even though these effects are not completely lethal, the impact on the organisms might lead to changes in their behavior, feeding habits, and consequently difficult survival in the natural environment.

Guimarães et al. ${ }^{184}$ studied the short-term exposure of juveniles of zebrafish to environmental microplastics with realistic concentrations and observed induced neurotoxicity and cytotoxicity to the specimens. Nevertheless, a wide number of toxicological studies are performed with a high concentration of microplastics and thus do not represent the real environmental conditions. ${ }^{185}$ This fact is supported by Izar et al., ${ }^{51}$ who found that the collected beached pellets induced toxicological effects in the sea urchin Lytechinus variegatus and the copepod Nitocra sp. at high pellet densities, however when applying real environmental concentrations, the beached pellets were not capable of promoting toxicity. In addition, Opitz et al. ${ }^{186}$ also observed that environmental concentrations of microplastics had a minimum impact on juvenile mussels. All these results indicate the current need to evaluate the risks associated with an environmental concentration of microplastics.

Despite the toxicity induced by ingested microplastics, the non-ingested effects are also crucial for animals exposed to these particles. Beached microplastics can leachate sorbed contaminants that can be highly toxic to organisms. Gandara e Silva et al. ${ }^{187}$ observed that collected beached pellets from the south coast of the São Paulo state (Paranapua and Itaquitanduva beaches) impaired completely the development of brown mussel embryos, while the virgin PP plastic pellets produced lower toxic effects. Acosta-Coley et al. ${ }^{158}$ also found similar results, extracts from Cartagena beached microplastics induced greater toxicity to Caenorhabditis elegans compared to virgin pellets, suggesting that contaminants sorbed on beached microplastics are responsible for the observed effects. On the other hand, Nobre et al. ${ }^{188}$ observed that the beached plastic pellets from Santos bay beaches induced less toxicological effect on the sea urchin larvae compared to virgin PE pellets. These results indicate that the degree of contamination of the environment, as well as the products incorporated in the plastic during its manufacturing process, are critical factors in the toxicity of the microplastics. The possible effects that these particles may cause still need urgent attention as they might induce 
long-term toxicological impacts. The behavioral changes caused by microplastics toxicity affect animals' survival in the environment and thus need to be further investigated.

\subsection{Chemical effect}

Beyond the physical impacts that contaminated particles provoke in the environment, the ingestion of these microplastics can induce greater toxic effects in biota as the contaminants transfer from the surface of plastic particles an animal organism. Colabuono et al. ${ }^{91}$ studied plastic pellets and fragments found in 97 individuals of 8 Procellariiformes species in Brazil. The authors found PCB and OC in both classes of microplastics. PCB was detected in concentrations higher than $243 \mathrm{ng} \mathrm{g}^{-1}$ and among the OC, dichloro diphenyl trichloro ethanes (DDT) had the highest concentrations reaching values above $64.4 \mathrm{ng} \mathrm{g}^{-1}$. The presence of these contaminants might promote its transference to the seabird's organism, as have already been reported by different authors. ${ }^{189,190}$ Roda et al. ${ }^{191}$ found that exposure to combined microplastics and copper resulted in genotoxicity, neurotoxicity, and physiological effects on neotropical teleost Prochilodus lineatus fish higher than the ones observed with isolated exposure to these contaminants. These results show the potential threat the association of microplastics, and environmental contaminants can pose to biota, as it can lead to more acute toxicological effects.

\subsection{Microbial effect}

Besides acting as a vector of organic and inorganic contaminants, microplastics can also serve as vehicles of microorganisms. Microplastic particles have high half-lives and their hydrophobic surface favors microbial colonization and biofilm formation which can potentially result in longdistance carriers of pathogenic microorganisms. ${ }^{60}$ Even though there is a lack of research on behalf of microbial community interaction with plastic debris in Latin America, some studies have already reported its potential risks. For example, Baptista Neto et al., ${ }^{60}$ investigated the potential contamination of bottom microplastics in Victoria Bay and found a plastisphere colonized mainly by bacteria, with some fungal filaments and spore, and Pazos et al., ${ }^{192}$ identify Escherichia coli and Enterococci on microplastics of the intertidal sediment of Río de la Plata. Silva et al. ${ }^{193}$ analyzed plastic debris larger than microplastics, in Guanabara Bay, and identified 44 bacteria strains confirmed as $E$. coli pathotypes and 59 strains of Vibrio species with 12 being identified as Vibrio cholerae, Vibrio vulnificus, and Vibrio mimicus. This debris can potentially become microplastics and serve as a substrate for these bacterial communities (including pathogens) that could pose a risk to human health and food security.

\subsection{Microplastics bioaccumulation}

Bioaccumulation of microplastics is of great concern, once some species are not able to rapidly excreted or egest these particles, resulting in the transference of microplastics through different trophic levels. The hypothesis is based on the likelihood of planktivorous fish to feed on microplastics that are similar to their prey in shape, size, and color, while large predatory fish are unlikely to target these particles, once their natural prey has superior sizes..$^{38}$ Therefore, the presence of these small particles in higher trophic levels would indicate the transference through prey-predator interaction. The research focused on the trophic transference of microplastics in Latin America is still limited, however, studies demonstrate the occurrence of this phenomenon. Laboratory studies on trophic transfer of microplastics have only been performed in Brazil, where there was evidenced transference in two and three-trophic levels. da Costa Araújo et al. ${ }^{194}$ demonstrated the transfer of PE microplastics from Poecilia reticulata fry (prey) to Danio rerio adults (predator) by identifying the PE microplastics in both prey and predator tissues. In the same way, da Costa Araújo and Malafaia ${ }^{195}$ reported the transference of PE microplastics from freshwater prey to terrestrial predators. They observed the transference of microplastics from Physalaemus cuvieri tadpoles to tambatinga fish and then to Swiss mice by identifying the particles in the individual's livers. Meanwhile, Lwanga et al. ${ }^{119}$ observed the microplastics concentration increase from the soil, to earthworms, to chickens in Mexico, which can be associated with the trophic transference of these particles through the food web. Some studies in Chile and Brazil, suggest that even though microplastics can be transferred to higher trophic levels, they can be egested and thus not stay accumulated. Chagnon et al..$^{38}$ investigated this assumption by analyzing Easter Island Thunnus albacares and their natural prey Cheilopogon rapanouiensis. The lack of microplastics in T. albacares digestive track while $16 \%$ of Cheilopogon rapanouiensis had ingested these particles suggests that if there is a trophic transference between the prey and the predator, the small particles might not accumulate. This is supported by Santana et al. ${ }^{196}$ who verified the trophic transfer of PVC microplastics from contaminated mussels to Callinectes ornatus crab and Spheoeroides greeleyi pufferfish. However, it was found that PVC particles were not persistent in the predators, as they were not found in their blood, tissues, or gut cavity after 10 days of depuration. This indicates that ingested 
microplastics might be eliminated through feces and excretion, reducing the risk of bioaccumulation.

\section{Conclusion and Recommendations}

The studies under review were from 16 Latin American countries, reaching $48 \%$ of the states that comprehend the whole Latin America (33 countries) territory. Microplastics were found in different studied matrices throughout the region. The sampling and treatment procedures employed were widely variable, which hinder the comparison among the studies. Most of the reviewed literature has not performed quality assurance and quality control measures. In general, most studies performed visual characterization and categorization of microplastics regarding shape, size, and color. It was observed that many of the studies that carried out chemical characterization were published in the last few years, which highlights the improvement of the research on this topic. Among the studies, the higher microplastic concentration was found in regions with high population densities and/or regions without proper sanitation and solid waste management. In addition, it was observed that the different sampling methods directly influence the amount of collected microplastics. Studies were mainly concentrated in marine matrices (59\%) rather than freshwater $(16 \%)$. Contaminants were found in beached microplastics in a wide range of concentrations. In general, laboratory studies have shown that microplastics induce toxicological effects on living organisms. In addition, microplastics have been identified as a potential vector in the transport of microorganisms through the environmental compartments. The laboratory investigation also showed that microplastics might be transferred among the trophic levels in the food chain, although in some organisms these particles are ingested directly and excreted.

Despite all these findings, there are still gaps regarding microplastics investigations in Latin America that need to be understood, as follow:

(i) Studies on microplastic contamination are urgently needed in more regions of Latin America, since there is insufficient data in Central America and the Caribbean region.

(ii) Airborne contamination is ubiquitous; $\mathrm{QA} / \mathrm{QC}$ measures are crucial to better represent the real contamination by microplastic in the different compartments. Therefore, it is recommended that studies regarding microplastic contamination should include QA/QC protocols to avoid overestimation of microplastics content in the results.

(iii) There is limited information about freshwater contamination in Latin America's ecosystems. More studies are needed in this area to enhance our understanding of the distribution, transport, and role of microplastics in the environment.

(iv) In the same way, most of the studied organisms are from marine environments, which highlights the need to perform more investigations on freshwater and terrestrial organisms. (v) The concentration of microplastic should be reported using standard and consistent units such as items $\mathrm{m}^{-3}$ or items $\mathrm{L}^{-1}$ for water samples, items $\mathrm{kg}^{-1}$ or items $\mathrm{g}^{-1}$ for sediment samples, and items ind ${ }^{-1}$ or items $\mathrm{g}^{-1}$ for biota. For the last ones, the information about the frequency of occurrence of microplastics in the individuals should also be recorded. (vi) Contaminants associated with microplastics reflect their possible transport through ecosystems and thus need more attention to the better understanding of the pathways, impacts, and effects of these contaminants on different ecosystems and living beings.

(vii) Only $44 \%$ of the studies focused on the chemical characterization of microplastics, thus the abundance of plastic particles in the environment might be overestimated. Therefore, the use of analytical techniques is highly recommended to identify polymeric composition.

Hence, the investigation concerning microplastic is important to enabling governments to establish public policies and regulations regarding plastic pollution and improve waste management strategies.

\section{Supplementary Information}

Supplementary data are available free of charge at http://jbcs.sbq.org.br as PDF file.

\section{Acknowledgments}

The authors thank the Coordination for the Improvement of Higher Education Personnel (CAPES, Finance Code 001) and National Institute for Advanced Analytical Science and Technology (INCTAA, CNPq proc. 465768/2014-8) for financial support.

\section{Author Contributions}

Andreia N. Fernandes was responsible for investigation, resources, writing-review and editing, supervision, project administration, funding acquisition; Crislaine Bertoldi for conceptualization, methodology, investigation, writing-original draft; Larissa Z. Lara for conceptualization, methodology, investigation, writing-original draft; Jéssica Stival for methodology, investigation; Nortom M. Alves for methodology, investigation; Pedro M. Cabrera for methodology, investigation; Marco T. Grassi for investigation, resources, writingreview and editing, supervision, project administration, funding acquisition. 


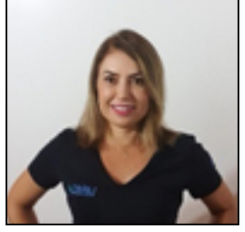

Andreia N. Fernandes obtained her PhD degree in 2007 in Chemistry from the Federal University of Santa Catarina. She was a postdoctoral fellow in the Chemistry department at Federal University of Paraná (20072009). Dr Fernandes is an Associate Professor of Chemistry at the Federal University of Rio Grande do Sul. Her research lines are about the microplastics in the environment; interaction of emerging contaminants with microplastics pristine and degraded; degradation of microplastics under $U V C, U V A$ radiations, and environmental conditions; removal of emerging contaminants from the aquatic environment; development and characterization of nanostructured materials for removal of emerging contaminants.

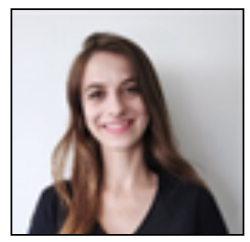

Crislaine Bertoldi received her bachelor's degree in Chemistry at the Federal Technological University of Paraná in 2015. She received her MSc (2017) in Chemistry Engineering at the Federal University of Rio Grande do Sul and currently works as a doctoral fellow in the research group of Prof Andreia N. Fernandes (2019-current) at the same University. Her research interests focus on the determination and characterization of microplastics in environmental matrices.

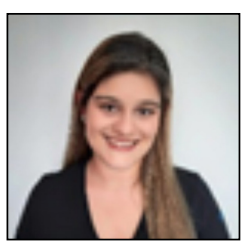

Larissa Z. Lara received her bachelor's degree in Industrial Chemistry at the University of Rio Grande do Sul, Brazil. She currently works as a master research fellow in Prof Andreia N. Fernandes's group (2019-current). Her research interests focus on the interaction of emerging contaminants with microplastics.

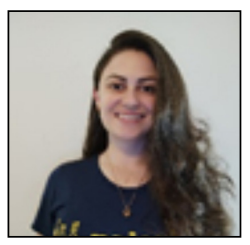

Jéssica Stival received her bachelor's degree in Chemistry at the Federal University of Paraná in 2017. She received her MSc (2019) in Chemistry at the Federal University of Paraná and currently works as a doctoral fellow in the research group of Prof Marco T. Grassi at the same University. Her research interests focus on environmental assessment, identification, and quantification of microplastics in natural water and their interactions with metallic species.

Nortom M. Alves is an undergraduate student in

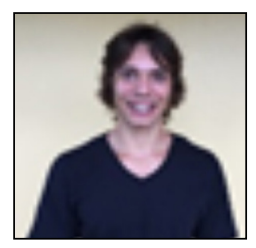

Industrial Chemistry at the University of Rio Grande do Sul, Brazil. His research interests focus on of the interaction of emerging contaminants with microplastics.

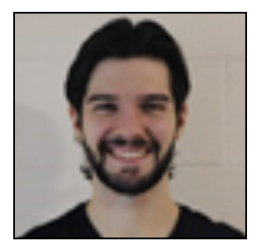

Pedro M. Cabrera is an undergraduate student in Industrial Chemistry at the University of Rio Grande do Sul, Brazil. His research interests focus on the determination and characterization of microplastics in environmental matrices.

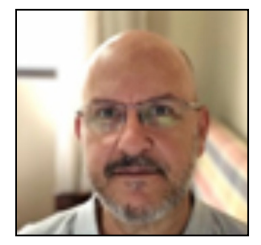

Marco T. Grassi received his PhD degree in Chemistry from Campinas State University in 1994, and then in 1998, he became a Faculty at the Federal University of Paraná. His main research interest is in environmental chemistry, with an emphasis on trace analysis and analytical chemistry. His work is focused on the following topics: water and sediment chemistry; metal and nonmetal speciation, behavior, and the fate of organic and inorganic contaminants in the environment, and development of passive samplers based on the concentration diffusive gradient in thin films (DGT) for the determination of emerging chemical contaminants in aquatic environments.

\section{References}

1. Meng, Y.; Kelly, F. J.; Wright, S. L.; Environ. Pollut. 2020, 256, 113445.

2. Wong, J. K. H.; Lee, K. K.; Tang, K. H. D.; Yap, P. S.; Sci. Total Environ. 2020, 719, 137512.

3. Geyer, R.; Jambeck, J. R.; Law, K. L.; Sci. Adv. 2017, 3, e1700782.

4. PlasticsEurope; Plastics-the Facts 2019; https://plasticseurope. org/wp-content/uploads/2021/10/2019-Plastics-the-facts.pdf, accessed in January 2022.

5. United Nations Environment Programme; Perspectiva de la Gestión de Residuos en América Latina y el Caribe; available at https://wedocs.unep.org/handle/20.500.11822/26448, accessed in January 2022.

6. Harlow, E.; Hurley, K.; Fox, A.; Vargas-Guerra, A.; Gibson, J.; Small-Scale \& Artisanal Mining Impacts on Biodiversity in Latin America; USAID, 2019, available at https://www. land-links.org/wp-content/uploads/2019/10/ASM_WhitePaper_USAID_FINAL_21March2019Final.pdf, accessed in January 2022. 
7. Kaza, S.; Yao, L.; Bhada-Tata, P.; van Woerden, F.; What a Waste 2.0: A Global Snapshot of Solid Waste Management to 2050, vol. 4; The World Bank: Washington DC, 2018.

8. Lebreton, L. C. M.; van der Zwet, J.; Damsteeg, J. W.; Slat, B.; Andrady, A.; Reisser, J.; Nat. Commun. 2017, 8, 15611.

9. Barnes, D. K. A.; Galgani, F.; Thompson, R. C.; Barlaz, M.; Philos. Trans. R. Soc., B 2009, 364, 1985.

10. Bläsing, M.; Amelung, W.; Sci. Total Environ. 2018, 612, 422.

11. Lusher, A. L.; Tirelli, V.; O’Connor, I.; Officer, R.; Sci. Rep. 2015, 5, 14947.

12. Peeken, I.; Primpke, S.; Beyer, B.; Gütermann, J.; Katlein, C.; Krumpen, T.; Bergmann, M.; Hehemann, L.; Gerdts, G.; Nat. Commun. 2018, 9, 12.

13. Peng, X.; Chen, M.; Chen, S.; Dasgupta, S.; Xu, H.; Ta, K.; Du, M.; Li, J.; Guo, Z.; Bai, S.; Geochem. Persp. Lett. 2018, 9,1 .

14. Wang, W.; Ndungu, A. W.; Li, Z.; Wang, J.; Sci. Total Environ. 2017, 575, 1369.

15. Free, C. M.; Jensen, O. P.; Mason, S. A.; Eriksen, M.; Williamson, N. J.; Boldgiv, B.; Mar. Pollut. Bull. 2014, 85, 156.

16. Eriksen, M.; Mason, S.; Wilson, S.; Box, C.; Zellers, A.; Edwards, W.; Farley, H.; Amato, S.; Mar. Pollut. Bull. 2013, 77, 177.

17. Andrady, A. L.; Mar. Pollut. Bull. 2017, 119, 12.

18. Cole, M.; Lindeque, P.; Halsband, C.; Galloway, T. S.; Mar. Pollut. Bull. 2011, 62, 2588.

19. Ma, H.; Pu, S.; Liu, S.; Bai, Y.; Mandal, S.; Xing, B.; Environ. Pollut. 2020, 261, 114089.

20. Rillig, M. C.; Kim, S. W.; Kim, T. Y.; Waldman, W. R.; Environ. Sci. Technol. 2021, 55, 2717.

21. Huang, W.; Song, B.; Liang, J.; Niu, Q.; Zeng, G.; Shen, M.; Deng, J.; Luo, Y.; Wen, X.; Zhang, Y.; J. Hazard. Mater. 2021, 405, 124187.

22. Amaral-Zettler, L. A.; Zettler, E. R.; Mincer, T. J.; Nat. Rev. Microbiol. 2020, 18, 139.

23. Ragusa, A.; Svelato, A.; Santacroce, C.; Catalano, P.; Notarstefano, V.; Carnevali, O.; Papa, F.; Rongioletti, M. C. A.; Baiocco, F.; Draghi, S.; D’Amore, E.; Rinaldo, D.; Matta, M.; Giorgini, E.; Environ. Int. 2021, 146, 106274.

24. Çobanoğlu, H.; Belivermiş, M.; Sıkdokur, E.; Kılıç, Ö.; Çayır, A.; Chemosphere 2021, 272, 129805.

25. Franco, A. A.; Arellano, J. M.; Albendín, G.; RodríguezBarroso, R.; Quiroga, J. M.; Coello, M. D.; Sci. Total Environ. 2021, 776, 145795.

26. He, D.; Chen, X.; Zhao, W.; Zhu, Z.; Qi, X.; Zhou, L.; Chen, W.; Wan, C.; Li, D.; Zou, X.; Wu, N.; Environ. Res. 2021, 196, 110908 .

27. Felismino, M. E. L.; Helm, P. A.; Rochman, C. M.; J. Great Lakes Res. 2021, 47, 180.

28. Chinfak, N.; Sompongchaiyakul, P.; Charoenpong, C.; Shi, H.; Yeemin, T.; Zhang, J.; Sci. Total Environ. 2021, 781, 146700.
29. Ivar do Sul, J. A.; Spengler, Â.; Costa, M. F.; Mar. Pollut. Bull. 2009, 58, 1236.

30. Brander, S. M.; Renick, V. C.; Foley, M. M.; Steele, C.; Woo, M.; Lusher, A.; Carr, S.; Helm, P.; Box, C.; Cherniak, S.; Andrews, R. C.; Rochman, C. M.; Appl. Spectrosc. 2020, 74, 1099.

31. Prata, J. C.; Reis, V.; da Costa, J. P.; Mouneyrac, C.; Duarte, A. C.; Rocha-Santos, T.; J. Hazard. Mater. 2021, 403, 123660.

32. Dehaut, A.; Hermabessiere, L.; Duflos, G.; TrAC, Trends Anal. Chem. 2019, 116, 346.

33. Frère, L.; Paul-Pont, I.; Rinnert, E.; Petton, S.; Jaffré, J.; Bihannic, I.; Soudant, P.; Lambert, C.; Huvet, A.; Environ. Pollut. 2017, 225, 211.

34. Ory, N. C.; Lehmann, A.; Javidpour, J.; Stöhr, R.; Walls, G. L.; Clemmesen, C.; Sci. Total Environ. 2020, 736, 139493.

35. Castro, R. O.; da Silva, M. L.; Marques, M. R. C.; de Araújo, F. V.; Mar. Pollut. Bull. 2020, 160, 111537.

36. Neto, J. G. B.; Rodrigues, F. L.; Ortega, I.; Rodrigues, L. S.; Lacerda, A. L. F.; Coletto, J. L.; Kessler, F.; Cardoso, L. G.; Madureira, L.; Proietti, M. C.; Environ. Pollut. 2020, 267, 115508.

37. Costa, M. F.; Ivar Do Sul, J. A.; Silva-Cavalcanti, J. S.; Araújo, M. C. B.; Spengler, Â.; Tourinho, P. S.; Environ. Monit. Assess. 2010, 168, 299.

38. Chagnon, C.; Thiel, M.; Antunes, J.; Ferreira, J. L.; Sobral, P.; Ory, N. C.; Environ. Pollut. 2018, 243, 127.

39. Santana, M. F. M.; Ascer, L. G.; Custódio, M. R.; Moreira, F. T.; Turra, A.; Mar. Pollut. Bull. 2016, 106, 183.

40. Dris, R.; Gasperi, J.; Saad, M.; Mirande, C.; Tassin, B.; Mar. Pollut. Bull. 2016, 104, 290.

41. Horton, A. A.; Walton, A.; Spurgeon, D. J.; Lahive, E.; Svendsen, C.; Sci. Total Environ. 2017, 586, 127.

42. Rodrigues, M. O.; Abrantes, N.; Gonçalves, F. J. M.; Nogueira, H.; Marques, J. C.; Gonçalves, A. M. M.; Sci. Total Environ. 2018, 633, 1549.

43. Birnstiel, S.; Soares-Gomes, A.; da Gama, B. A. P.; Mar. Pollut. Bull. 2019, 140, 241.

44. Pazos, R. S.; Spaccesi, F.; Gómez, N.; Reg. Stud. Mar. Sci. 2020, $38,101360$.

45. Stock, F.; Kochleus, C.; Bänsch-Baltruschat, B.; Brennholt, N.; Reifferscheid, G.; TrAC, Trends Anal. Chem. 2019, 113, 84.

46. Figueiredo, G. M.; Vianna, T. M. P.; Mar. Pollut. Bull. 2018, 135, 256.

47. Prata, J. C.; da Costa, J. P.; Duarte, A. C.; Rocha-Santos, T.; TrAC, Trends Anal. Chem. 2019, 110, 150.

48. Liu, Y.; You, J.; Li, Y.; Zhang, J.; He, Y.; Breider, F.; Tao, S.; Liu, W.; Sci. Total Environ. 2021, 779, 146589.

49. Chen, C. F.; Ju, Y. R.; Lim, Y. C.; Chen, C. W.; Dong, C.-D.; Sci. Total Environ. 2021, 781, 146610.

50. James, K.; Vasant, K.; Sikkander Batcha, S. M.; Padua, S.; Jeyabaskaran, R.; Thirumalaiselvan, S.; Vineetha, G.; Benjamin, L. V.; Reg. Stud. Mar. Sci. 2021, 41, 101558. 
51. Izar, G. M.; Morais, L. G.; Pereira, C. D. S.; Cesar, A.; Abessa, D. M. S.; Christofoletti, R. A.; Reg. Stud. Mar. Sci. 2019, 29 , 100705.

52. Turra, A.; Manzano, A. B.; Dias, R. J. S.; Mahiques, M. M.; Barbosa, L.; Balthazar-Silva, D.; Moreira, F. T.; Sci. Rep. 2014, 4, 4435.

53. Martinelli Filho, J. E.; Monteiro, R. C. P.; Mar. Pollut. Bull. 2019, 145, 219.

54. Lusher, A. L.; Welden, N. A.; Sobral, P.; Cole, M.; Anal. Methods 2017, 9, 1346.

55. Montecinos, S.; Tognana, S.; Pereyra, M.; Silva, L.; Tomba, J. P.; Sci. Total Environ. 2021, 760, 143390.

56. Ramírez-Álvarez, N.; Rios Mendoza, L. M.; Macías-Zamora, J. V.; Oregel-Vázquez, L.; Alvarez-Aguilar, A.; HernándezGuzmán, F. A.; Sánchez-Osorio, J. L.; Moore, C. J.; SilvaJiménez, H.; Navarro-Olache, L. F.; Sci. Total Environ. 2020, 703, 134838.

57. Ronda, A. C.; Arias, A. H.; Oliva, A. L.; Marcovecchio, J. E.; Mar. Pollut. Bull. 2019, 149, 110618.

58. Baptista Neto, J. A.; de Carvalho, D. G.; Medeiros, K.; Drabinski, T. L.; de Melo, G. V.; Silva, R. C. O.; Silva, D. C. P.; de Sousa Batista, L.; Dias, G. T. M.; da Fonseca, E. M.; dos Santos Filho, J. R.; Mar. Pollut. Bull. 2019, 149, 110558.

59. Alves, V. E. N.; Figueiredo, G. M.; Mar. Pollut. Bull. 2019, 146, 326.

60. Baptista Neto, J. A.; Gaylarde, C.; Beech, I.; Bastos, A. C.; da Silva Quaresma, V.; de Carvalho, D. G.; Ocean Coastal Manage. 2019, 169, 247.

61. Fernández Severini, M. D.; Buzzi, N. S.; Forero López, A. D.; Colombo, C. V.; Chatelain Sartor, G. L.; Rimondino, G. N.; Truchet, D. M.; Mar. Pollut. Bull. 2020, 161, 111700.

62. Hara, J.; Frias, J.; Nash, R.; Mar. Pollut. Bull. 2020, 152, 110905.

63. Thiele, C. J.; Hudson, M. D.; Russell, A. E.; Mar. Pollut. Bull. 2019, 142, 384.

64. Nuelle, M. T.; Dekiff, J. H.; Remy, D.; Fries, E.; Environ. Pollut. 2014, 184, 161.

65. Fernández Severini, M. D.; Villagran, D. M.; Buzzi, N. S.; Sartor, G. C.; Reg. Stud. Mar. Sci. 2019, 32, 100829.

66. Pozo, K.; Gomez, V.; Torres, M.; Vera, L.; Nuñez, D.; Oyarzún, P.; Mendoza, G.; Clarke, B.; Fossi, M. C.; Baini, M.; Přibylová, P.; Klánová, J.; Mar. Pollut. Bull. 2019, 140, 315.

67. Silva, P. M.; Nanny, M. A.; Water (Switzerland) 2020, 12, 1210.

68. Corradini, F.; Meza, P.; Eguiluz, R.; Casado, F.; Huerta-Lwanga, E.; Geissen, V.; Sci. Total Environ. 2019, 671, 411.

69. Veerasingam, S.; Ranjani, M.; Venkatachalapathy, R.; Bagaev, A.; Mukhanov, V.; Litvinyuk, D.; Verzhevskaia, L.; Guganathan, L.; Vethamony, P.; TrAC, Trends Anal. Chem. 2020, 133, 116071.

70. Fok, L.; Lam, T. W. L.; Li, H. X.; Xu, X. R.; Sci. Total Environ. 2020, 718, 135371.

71. Helm, P. A.; Anal. Methods 2017, 9, 1328.
72. Fahrenfeld, N. L.; Arbuckle-Keil, G.; Naderi Beni, N.; BarteltHunt, S. L.; TrAC, Trends Anal. Chem. 2019, 112, 248.

73. Gusmão, F.; di Domenico, M.; Amaral, A. C. Z.; Martínez, A.; Gonzalez, B. C.; Worsaae, K.; Ivar do Sul, J. A.; Lana, P. C.; Environ. Pollut. 2016, 216, 584.

74. Pegado, T. S. S.; Schmid, K.; Winemiller, K. O.; Chelazzi, D.; Cincinelli, A.; Dei, L.; Giarrizzo, T.; Mar. Pollut. Bull. 2018, $133,814$.

75. De-la-Torre, G. E.; Dioses-Salinas, D. C.; Castro, J. M.; Antay, R.; Fernández, N. Y.; Espinoza-Morriberón, D.; SaldañaSerrano, M.; Mar. Pollut. Bull. 2020, 151, 110877.

76. Andrade, M. C.; Winemiller, K. O.; Barbosa, P. S.; Fortunati, A.; Chelazzi, D.; Cincinelli, A.; Giarrizzo, T.; Environ. Pollut. 2019, 244, 766.

77. Li, R.; Zhang, L.; Xue, B.; Wang, Y.; Environ. Pollut. 2019 , 244,685 .

78. Ferreira, G. V. B.; Barletta, M.; Lima, A. R. A.; Morley, S. A.; Justino, A. K. S.; Costa, M. F.; Environ. Pollut. 2018, 236, 706.

79. Ríos, M. F.; Hernández-Moresino, R. D.; Galván, D. E.; Mar. Pollut. Bull. 2020, 159, 111491.

80. Blettler, M. C. M.; Garello, N.; Ginon, L.; Abrial, E.; Espinola, L. A.; Wantzen, K. M.; Environ. Pollut. 2019, 255, 113348.

81. Vendel, A. L.; Bessa, F.; Alves, V. E. N.; Amorim, A. L. A.; Patrício, J.; Palma, A. R. T.; Mar. Pollut. Bull. 2017, 117, 448.

82. Cesa, F. S.; Turra, A.; Checon, H. H.; Leonardi, B.; BaruqueRamos, J.; Environ. Pollut. 2020, 257, 113553.

83. Ivar do Sul, J. A.; Costa, M. F.; Environ. Pollut. 2014, 185, 352.

84. Moruzzi, R. B.; Speranza, L. G.; da Conceição, F. T.; de Souza Martins, S. T.; Busquets, R.; Campos, L. C.; Water (Switzerland) 2020, 12, 1994.

85. Acosta-Coley, I.; Duran-Izquierdo, M.; Rodriguez-Cavallo, E.; Mercado-Camargo, J.; Mendez-Cuadro, D.; Olivero-Verbel, J.; Mar. Pollut. Bull. 2019, 146, 574

86. Castro, R. O.; Silva, M. L.; Marques, M. R. C.; de Araújo, F. V.; Mar. Pollut. Bull. 2016, 110, 555.

87. Lima, A. R. A.; Barletta, M.; Costa, M. F.; Estuarine, Coastal Shelf Sci. 2015, 165, 213.

88. Rodríguez, C.; Fossatti, M.; Carrizo, D.; Sánchez-García, L.; Teixeira de Mello, F.; Weinstein, F.; Lozoya, J. P.; Sci. Total Environ. 2020, 721, 137734.

89. Pazos, R. S.; Maiztegui, T.; Colautti, D. C.; Paracampo, A. H.; Gómez, N.; Mar. Pollut. Bull. 2017, 122, 85.

90. del Carmen Alejo-Plata, M.; Herrera-Galindo, E.; CruzGonzález, D. G.; Mar. Pollut. Bull. 2019, 142, 504.

91. Colabuono, F. I.; Taniguchi, S.; Montone, R. C.; Mar. Pollut. Bull. 2010, 60, 630.

92. Picó, Y.; Barceló, D.; ACS Omega 2019, 4, 6709.

93. Sun, J.; Dai, X.; Wang, Q.; van Loosdrecht, M. C. M.; Ni, B.-J.; Water Res. 2019, 152, 21.

94. Xu, J.-L.; Thomas, K. V.; Luo, Z.; Gowen, A. A.; TrAC, Trends Anal. Chem. 2019, 115629. 
95. Picó, Y.; Barceló, D.; ACS Omega 2019, 4, 6709.

96. Piñon-Colin, T. J.; Rodriguez-Jimenez, R.; Rogel-Hernandez, E.; Alvarez-Andrade, A.; Wakida, F. T.; Sci. Total Environ. 2020, 704, 135411.

97. Ivar do Sul, J. A.; Costa, M. F.; Barletta, M.; Cysneiros, F. J. A.; Mar. Pollut. Bull. 2013, 75, 305.

98. Monteiro, R. C. P.; Ivar do Sul, J. A.; Costa, M. F.; Ocean Coastal Res. 2020, 68, e20235.

99. Garcés-Ordóñez, O.; Castillo-Olaya, V. A.; Granados-Briceño, A. F.; Blandón García, L. M.; Espinosa Díaz, L. F.; Mar. Pollut. Bull. 2019, 145, 455.

100. Pegado, T.; Brabo, L.; Schmid, K.; Sarti, F.; Gava, T. T.; Nunes, J.; Chelazzi, D.; Cincinelli, A.; Giarrizzo, T.; Mar. Pollut. Bull. 2021, 162, 111799.

101. Agência Nacional de Águas (ANA); Atlas Esgotos Despoluição de Bacias Hidrográficas; ANA: Brasília, 2017; available at http://arquivos.ana.gov.br/imprensa/publicacoes/ATLASeESG OTOSDespoluicaodeBaciasHidrograficas-ResumoExecutivo_ livro.pdf, accessed in January 2022.

102. Olivatto, G. P.; Martins, M. C. T.; Montagner, C. C.; Henry, T. B.; Carreira, R. S.; Mar. Pollut. Bull. 2019, 139, 157.

103. Soares-Gomes, A.; da Gama, B. A. P.; Baptista Neto, J. A.; Freire, D. G.; Cordeiro, R. C.; Machado, W.; Bernardes, M. C.; Coutinho, R.; Thompson, F. L.; Pereira, R. C.; Reg. Stud. Mar. Sci. 2016, 8, 319.

104. Portz, L.; Manzolli, R. P.; Herrera, G. V.; Garcia, L. L.; Villate, D. A.; Ivar do Sul, J. A.; Mar. Pollut. Bull. 2020, 157, 111323.

105. Ivar do Sul, J. A.; Costa, M. F.; Fillmann, G.; Water, Air, Soil Pollut. 2014, 225, 2004.

106. Forero López, A. D.; Truchet, D. M.; Rimondino, G. N.; Maisano, L.; Spetter, C. V.; Buzzi, N. S.; Nazzarro, M. S.; Malanca, F. E.; Furlong, O.; Fernández Severini, M. D.; Sci. Total Environ. 2021, 754, 142413.

107. Pazos, R. S.; Bauer, D. E.; Gómez, N.; Environ. Pollut. 2018, 243, 134.

108. Castillo, C.; Fernández, C.; Gutiérrez, M. H.; Aranda, M.; Urbina, M. A.; Yáñez, J.; Álvarez, Á.; Pantoja-Gutiérrez, S.; Mar. Pollut. Bull. 2020, 160, 111591.

109. Ferraz, M.; Bauer, A. L.; Valiati, V. H.; Schulz, U. H.; Water (Switzerland) 2020, 12, 3115.

110. Bertoldi, C.; Lara, L. Z.; Mizushima, F. A. L.; Martins, F. C. G.; Battisti, M. A.; Hinrichs, R.; Fernandes, A. N.; Sci. Total Environ. 2021, 759, 143503.

111. Correa-Herrera, T.; Barletta, M.; Lima, A. R. A.; JiménezSegura, L. F.; Arango-Sánchez, L. B.; J. Fish Biol. 2017, 90, 1356.

112. Alfonso, M. B.; Scordo, F.; Seitz, C.; Mavo Manstretta, G. M.; Ronda, A. C.; Arias, A. H.; Tomba, J. P.; Silva, L. I.; Perillo, G. M. E.; Piccolo, M. C.; Sci. Total Environ. 2020, 733, 139385.

113. Zhang, C.; Wang, S.; Sun, D.; Pan, Z.; Zhou, A.; Xie, S.; Wang, J.; Zou, J.; Chemosphere 2020, 256, 127202.
114. Kashiwabara, L. M.; Kahane-Rapport, S. R.; King, C.; DeVogelaere, M.; Goldbogen, J. A.; Savoca, M. S.; Mar. Pollut. Bull. 2021, 165, 112148.

115. Jian, M.; Zhang, Y.; Yang, W.; Zhou, L.; Liu, S.; Xu, E. G.; Chemosphere 2020, 261, 128186.

116. Garcés-Ordóñez, O.; Espinosa, L. F.; Cardoso, R. P.; Issa Cardozo, B. B.; Meigikos dos Anjos, R.; Environ. Pollut. 2020, 267, 115495.

117. de Carvalho, D. G.; Baptista Neto, J. A.; Ocean Coastal Manage. 2016, 128,10 .

118. Mitchell, C.; Quaglino, M. C.; Posner, V. M.; Arranz, S. E.; Sciara, A. A.; Environ. Sci. Pollut. Res. 2021, 28, 16140.

119. Lwanga, E. H.; Vega, J. M.; Quej, V. K.; Chi, J. A.; del Cid, L. S.; Chi, C.; Segura, G. E.; Gertsen, H.; Salánki, T.; van der Ploeg, M.; Koelmans, A. A.; Geissen, V.; Sci. Rep. 2017, 7, 14071.

120. Corradini, F.; Casado, F.; Leiva, V.; Huerta-Lwanga, E.; Geissen, V.; Sci. Total Environ. 2021, 752, 141917.

121. Álvarez-Lopeztello, J.; Robles, C.; del Castillo, R. F.; Ecol. Indic. 2021, 121, 107084.

122. Helcoski, R.; Yonkos, L. T.; Sanchez, A.; Baldwin, A. H.; Environ. Pollut. 2020, 256, 113391.

123. Chen, Y.; Leng, Y.; Liu, X.; Wang, J.; Environ. Pollut. 2020, $257,113449$.

124. Gerolin, C. R.; Pupim, F. N.; Sawakuchi, A. O.; Grohmann, C. H.; Labuto, G.; Semensatto, D.; Sci. Total Environ. 2020, 749, 141604.

125. Cordova, M. R.; Ulumuddin, Y. I.; Purbonegoro, T.; Shiomoto, A.; Mar. Pollut. Bull. 2021, 163, 112012.

126. Goswami, P.; Vinithkumar, N. V.; Dharani, G.; Mar. Pollut. Bull. 2021, 167, 112311.

127. Haave, M.; Lorenz, C.; Primpke, S.; Gerdts, G.; Mar. Pollut. Bull. 2019, 141, 501.

128. Phuong, N. N.; Poirier, L.; Lagarde, F.; Kamari, A.; ZaloukVergnoux, A.; Environ. Pollut. 2018, 243, 228.

129. Cincinelli, A.; Scopetani, C.; Chelazzi, D.; Martellini, T.; Pogojeva, M.; Slobodnik, J.; Sci. Total Environ. 2021, 760, 143898.

130. Fu, Z.; Chen, G.; Wang, W.; Wang, J.; Environ. Pollut. 2020, 266, 115098 .

131. Arias, A. H.; Ronda, A. C.; Oliva, A. L.; Marcovecchio, J. E.; Bull. Environ. Contam. Toxicol. 2019, 102, 750.

132. Perez-Venegas, D. J.; Toro-Valdivieso, C.; Ayala, F.; Brito, B.; Iturra, L.; Arriagada, M.; Seguel, M.; Barrios, C.; Sepúlveda, M.; Oliva, D.; Cárdenas-Alayza, S.; Urbina, M. A.; Jorquera, A.; Castro-Nallar, E.; Galbán-Malagón, C.; Mar. Pollut. Bull. 2020, 153, 110966.

133. Bermúdez-Guzmán, L.; Alpízar-Villalobos, C.; GatgensGarcía, J.; Jiménez-Huezo, G.; Rodríguez-Arias, M.; Molina, H.; Villalobos, J.; Paniagua, S. A.; Vega-Baudrit, J. R.; RojasJimenez, K.; Reg. Stud. Mar. Sci. 2020, 38, 101367. 
134. Silva, J. D. B.; Barletta, M.; Lima, A. R. A.; Ferreira, G. V. B.; Environ. Pollut. 2018, 242, 1010.

135. Dantas, D. V.; Barletta, M.; da Costa, M. F.; Environ. Sci. Pollut. Res. 2012, 19, 600.

136. de Amorim, A. L. A.; Ramos, J. A. A.; Nogueira Jr., M.; Mar. Pollut. Bull. 2020, 158, 111214.

137. Tourinho, P. S.; Ivar do Sul, J. A.; Fillmann, G.; Mar. Pollut. Bull. 2010, 60, 396.

138. Ory, N.; Chagnon, C.; Felix, F.; Fernández, C.; Ferreira, J. L.; Gallardo, C.; Garcés Ordóñez, O.; Henostroza, A.; Laaz, E.; Mizraji, R.; Mojica, H.; Murillo Haro, V.; Ossa Medina, L.; Preciado, M.; Sobral, P.; Urbina, M. A.; Thiel, M.; Mar. Pollut. Bull. 2018, 127, 211.

139. Garcés-Ordóñez, O.; Mejía-Esquivia, K. A.; Sierra-Labastidas, T.; Patiño, A.; Blandón, L. M.; Espinosa Díaz, L. F.; Mar. Pollut. Bull. 2020, 154, 111085.

140. Silva-Cavalcanti, J. S.; Silva, J. D. B.; de França, E. J.; de Araújo, M. C. B.; Gusmão, F.; Environ. Pollut. 2017, 221, 218.

141. Andreas; Hadibarata, T.; Sathishkumar, P.; Prasetia, H.; Hikmat; Pusfitasari, E. D.; Tasfiyati, A. N.; Muzdalifah, D.; Waluyo, J.; Randy, A.; Ramadhaningtyas, D. P.; Zuas, O.; Sari, A. A.; Chemosphere 2021, 276, 130185.

142. Filgueiras, A. V.; Preciado, I.; Cartón, A.; Gago, J.; Mar. Pollut. Bull. 2020, 160, 111623.

143. Weitzel, S. L.; Feura, J. M.; Rush, S. A.; Iglay, R. B.; Woodrey, M. S.; Mar. Pollut. Bull. 2021, 166, 112187.

144. Cordova, M. R.; Riani, E.; Shiomoto, A.; Mar. Pollut. Bull. 2020, 161, 111763.

145. Herrera, A.; Ŝtindlová, A.; Martínez, I.; Rapp, J.; RomeroKutzner, V.; Samper, M. D.; Montoto, T.; Aguiar-González, B.; Packard, T.; Gómez, M.; Mar. Pollut. Bull. 2019, 139, 127.

146. Pérez, A. F.; Ojeda, M.; Rimondino, G. N.; Chiesa, I. L.; Di Mauro, R.; Boy, C. C.; Calcagno, J. A.; Mar. Pollut. Bull. 2020 , $161,111753$.

147. Costa, L. L.; Arueira, V. F.; da Costa, M. F.; di Beneditto, A. P. M.; Zalmon, I. R.; Mar. Pollut. Bull. 2019, 145, 5.

148. De-la-torre, G. E.; Vargas, D. A.; Rev. Biol. Mar. Oceanogr. 2020, 55, 167.

149. Digka, N.; Tsangaris, C.; Torre, M.; Anastasopoulou, A.; Zeri, C.; Mar. Pollut. Bull. 2018, 135, 30.

150. Leslie, H. A.; van Velzen, M. J. M.; Vethaak, A. D.; Microplastic Survey of the Dutch Environment: Novel Data Set of Microplastics in North Sea Sediments, Treated Wastewater Effluents and Marine Biota; IVM Institute for Environmental Studies: Amsterdam, 2013.

151. Mizraji, R.; Ahrendt, C.; Perez-Venegas, D.; Vargas, J.; Pulgar, J.; Aldana, M.; Patricio Ojeda, F.; Duarte, C.; Galbán-Malagón, C.; Mar. Pollut. Bull. 2017, 116, 498.

152. Gorman, D.; Moreira, F. T.; Turra, A.; Fontenelle, F. R.; Combi, T.; Bícego, M. C.; de Castro Martins, C.; Chemosphere 2019, $223,608$.
153. Mei, W.; Chen, G.; Bao, J.; Song, M.; Li, Y.; Luo, C.; Sci. Total Environ. 2020, 736, 139472.

154. Shruti, V. C.; Jonathan, M. P.; Rodriguez-Espinosa, P. F.; Rodríguez-González, F.; Sci. Total Environ. 2019, 654, 154.

155. Vedolin, M. C.; Teophilo, C. Y. S.; Turra, A.; Figueira, R. C. L.; Mar. Pollut. Bull. 2018, 129, 487.

156. Holmes, L. A.; Turner, A.; Thompson, R. C.; Environ. Pollut. 2012, 160, 42 .

157. Maršić-Lučić, J.; Lušić, J.; Tutman, P.; Bojanić Varezić, D.; Šiljić, J.; Pribudić, J.; Mar. Pollut. Bull. 2018, 137, 231.

158. Acosta-Coley, I.; Mendez-Cuadro, D.; Rodriguez-Cavallo, E.; de la Rosa, J.; Olivero-Verbel, J.; Mar. Pollut. Bull. 2019, 139, 402.

159. Antunes, J. C.; Frias, J. G. L.; Micaelo, A. C.; Sobral, P.; Estuarine, Coastal Shelf Sci. 2013, 130, 62.

160. Camacho, M.; Herrera, A.; Gómez, M.; Acosta-Dacal, A.; Martínez, I.; Henríquez-Hernández, L. A.; Luzardo, O. P.; Sci. Total Environ. 2019, 662, 22.

161. Frias, J. P. G. L.; Sobral, P.; Ferreira, A. M.; Mar. Pollut. Bull. 2010, 60, 1988.

162. Karapanagioti, H. K.; Endo, S.; Ogata, Y.; Takada, H.; Mar. Pollut. Bull. 2011, 62, 312.

163. Pannetier, P.; Cachot, J.; Clérandeau, C.; Faure, F.; van Arkel, K.; de Alencastro, L. F.; Levasseur, C.; Sciacca, F.; Bourgeois, J. P.; Morin, B.; Environ. Pollut. 2019, 248, 1088.

164. Ryan, P. G.; Bouwman, H.; Moloney, C. L.; Yuyama, M.; Takada, H.; Mar. Pollut. Bull. 2012, 64, 2756.

165. Zhang, W.; Ma, X.; Zhang, Z.; Wang, Y.; Wang, J.; Wang, J.; Ma, D.; Mar. Pollut. Bull. 2015, 99, 28.

166. Shi, J.; Sanganyado, E.; Wang, L.; Li, P.; Li, X.; Liu, W.; Ecotoxicol. Environ. Saf. 2020, 193, 110356.

167. Lozoya, J. P.; de Mello, F. T.; Carrizo, D.; Weinstein, F.; Olivera, Y.; Cedrés, F.; Pereira, M.; Fossati, M.; Environ. Pollut. 2016, $218,931$.

168. Fisner, M.; Taniguchi, S.; Moreira, F.; Bícego, M. C.; Turra, A.; Mar. Pollut. Bull. 2013, 70, 219.

169. Fisner, M.; Taniguchi, S.; Majer, A. P.; Bícego, M. C.; Turra, A.; Mar. Pollut. Bull. 2013, 76, 349.

170. Taniguchi, S.; Colabuono, F. I.; Dias, P. S.; Oliveira, R.; Fisner, M.; Turra, A.; Izar, G. M.; Abessa, D. M. S.; Saha, M.; Hosoda, J.; Yamashita, R.; Takada, H.; Lourenço, R. A.; Magalhães, C. A.; Bícego, M. C.; Montone, R. C.; Mar. Pollut. Bull. 2016, 106, 87.

171. Fisner, M.; Majer, A.; Taniguchi, S.; Bícego, M.; Turra, A.; Gorman, D.; Mar. Pollut. Bull. 2017, 122, 323.

172. Brennecke, D.; Ferreira, E. C.; Costa, T. M. M.; Appel, D.; da Gama, B. A. P.; Lenz, M.; Mar. Pollut. Bull. 2015, 96, 491.

173. Habibullah-Al-Mamun, M.; Kawser Ahmed, M.; Hossain, A.; Masunaga, S.; Arch. Environ. Contam. Toxicol. 2019, 76, 178.

174. Pozo, K.; Urbina, W.; Gómez, V.; Torres, M.; Nuñez, D.; Přibylová, P.; Audy, O.; Clarke, B.; Arias, A.; Tombesi, N.; Guida, Y.; Klánová, J.; Mar. Pollut. Bull. 2020, 151, 110786. 
175. Carrasco, A.; Pulgar, J.; Quintanilla-Ahumada, D.; Perez-Venegas, D.; Quijón, P. A.; Duarte, C.; Mar. Pollut. Bull. 2019, 145, 23.

176. de Barros, M. S. F.; Calado, T. C. S.; de Araújo, M. S. L. C.; Mar. Pollut. Bull. 2020, 156, 111249.

177. Wilcox, C.; van Sebille, E.; Hardesty, B. D.; Proc. Natl. Acad. Sci. U.S.A. 2015, 112, 11899.

178. Boyero, L.; López-Rojo, N.; Bosch, J.; Alonso, A.; Correa-Araneda, F.; Pérez, J.; Chemosphere 2020, 244, 125500.

179. Welden, N. A. C.; Cowie, P. R.; Environ. Pollut. 2016, $218,895$.

180. Rossi, L. C.; Scherer, A. L.; Petry, M. V.; Mar. Pollut. Bull. 2019, 138, 235.

181. Malafaia, G.; de Souza, A. M.; Pereira, A. C.; Gonçalves, S.; Araújo, A. P. C.; Ribeiro, R. X.; Rocha, T. L.; Sci. Total Environ. 2020, 700, 134867

182. Araújo, A. P. C.; Malafaia, G.; J. Hazard. Mater. 2020, 391, 122214.

183. da Costa Araújo, A. P.; de Melo, N. F. S.; de Oliveira Jr., A. G.; Rodrigues, F. P.; Fernandes, T.; Vieira, J. E. A.; Rocha, T. L.; Malafaia, G.; J. Hazard. Mater. 2020, 382, 121066.

184. Guimarães, A. T. B.; Charlie-Silva, I.; Malafaia, G.; J. Hazard. Mater. 2021, 407, 124833.

185. Jovanović, B.; Gökdağ, K.; Güven, O.; Emre, Y.; Whitley, E. M.; Kideys, A. E.; Mar. Pollut. Bull. 2018, 130, 123.

186. Opitz, T.; Benítez, S.; Fernández, C.; Osores, S.; Navarro, J. M.; Rodríguez-Romero, A.; Lohrmann, K. B.; Lardies, M. A.; Mar. Pollut. Bull. 2021, 162, 111834.
187. Gandara e Silva, P. P.; Nobre, C. R.; Resaffe, P.; Pereira, C. D. S.; Gusmão, F.; Water Res. 2016, 106, 364.

188. Nobre, C. R.; Santana, M. F. M.; Maluf, A.; Cortez, F. S.; Cesar, A.; Pereira, C. D. S.; Turra, A.; Mar. Pollut. Bull. 2015, 92, 99.

189. Ryan, P. G.; Connell, A. D.; Gardner, B. D.; Mar. Pollut. Bull. 1988, 19, 174.

190. Tanaka, K.; Takada, H.; Yamashita, R.; Mizukawa, K.; Fukuwaka, M.; Watanuki, Y.; Mar. Pollut. Bull. 2013, 69, 219.

191. Roda, J. F. B.; Lauer, M. M.; Risso, W. E.; Bueno dos Reis Martinez, C.; Comp. Biochem. Physiol., Part A: Mol. Integr. Physiol. 2020, 242, 110659.

192. Pazos, R. S.; Suárez, J. C.; Gómez, N.; Ecosistemas 2020, $29,1$.

193. Silva, M. M.; Maldonado, G. C.; Castro, R. O.; Felizardo, J. S.; Cardoso, R. P.; dos Anjos, R. M.; de Araújo, F. V.; Mar. Pollut. Bull. 2019, 141, 561.

194. da Costa Araújo, A. P.; de Andrade Vieira, J. E.; Malafaia, G.; Sci. Total Environ. 2020, 742, 140217.

195. da Costa Araújo, A. P.; Malafaia, G.; J. Hazard. Mater. 2021, 401,123263

196. Santana, M. F. M.; Moreira, F. T.; Turra, A.; Mar. Pollut. Bull. 2017, 121, 154.

Submitted: September 10, 2021

Published online: January 26, 2022 